\title{
CD27 signaling on chronic myelogenous leukemia stem cells activates Wnt target genes and promotes disease progression
}

\author{
Christian Schürch, ${ }^{1}$ Carsten Riether, ${ }^{1}$ Matthias S. Matter, ${ }^{2}$ \\ Alexandar Tzankov, ${ }^{2}$ and Adrian F. Ochsenbein ${ }^{1,3}$
}

\begin{abstract}
${ }^{1}$ Tumor Immunology, Department of Clinical Research, University of Bern, Bern, Switzerland. 2Institute of Pathology, University Hospital Basel, Basel, Switzerland. ${ }^{3}$ Institute for Medical Oncology, Inselspital, University Hospital Bern, Bern, Switzerland.
\end{abstract}

\begin{abstract}
Chronic myelogenous leukemia (CML) results from a chromosomal translocation in hematopoietic stem or early progenitor cells that gives rise to the oncogenic BCR/ABL fusion protein. Clinically, CML has a chronic phase that eventually evolves into an accelerated stage and blast crisis. A CML-specific immune response is thought to contribute to the control of disease. Whether the immune system can also promote disease progression is not known. In the present study, we investigated the possibility that the TNF receptor family member CD27 is present on leukemia stem cells (LSCs) and mediates effects of the immune system on CML. In a mouse model of CML, BCR/ABL ${ }^{+}$LSCs and leukemia progenitor cells were found to express CD27. Binding of CD27 by its ligand, CD70, increased expression of Wnt target genes in LSCs by enhancing nuclear localization of active $\beta$-catenin and TRAF2- and NCK-interacting kinase (TNIK). This resulted in increased proliferation and differentiation of LSCs. Blocking CD27 signaling in LSCs delayed disease progression and prolonged survival. Furthermore, CD27 was expressed on CML stem/progenitor cells in the bone marrow of CML patients, and CD27 signaling promoted growth of $\mathrm{BCR} / \mathrm{ABL}^{+}$human leukemia cells by activating the Wnt pathway. Since expression of CD70 is limited to activated lymphocytes and dendritic cells, our results reveal a mechanism by which adaptive immunity contributes to leukemia progression. In addition, targeting CD27 on LSCs may represent an attractive therapeutic approach to blocking the Wnt/ $\beta$-catenin pathway in CML.
\end{abstract}

\section{Introduction}

Chronic myelogenous leukemia (CML) is associated with the Philadelphia $\left(\mathrm{Ph}^{\prime}\right)$ chromosome, a reciprocal translocation between chromosomes 9 and $22[\mathrm{t}(9 ; 22)(\mathrm{q} 34.1 ; \mathrm{q} 11.21)](1) . \mathrm{Ph}^{\prime}$ leads to the formation of the oncogenic BCR/ABL fusion protein, a constitutively active tyrosine kinase that is necessary and sufficient for malignant transformation (2). The BCR/ABL translocation arises in hematopoietic stem or early progenitor cells known as leukemia stem cells (LSCs) (3). Clinically, CML has a chronic phase characterized by dysregulated production and accumulation of mature granulocytes and eventually evolves into the accelerated stage and blast crisis through acquisition of further genetic abnormalities (4).

Clinical and experimental evidence suggests that CML elicits leukemia-specific immunity that contributes to the control of the disease. Cytotoxic CD8 ${ }^{+} \mathrm{T}$ lymphocytes (CTLs) directed against leukemia antigens were detected in the blood of CML patients (5). Several proteins may potentially act as leukemiaspecific antigens for $\mathrm{T}$ cells, including $\mathrm{BCR} / \mathrm{ABL}$, Wilms tumor 1 protein (WT1), proteinase $3(\operatorname{Pr} 3)$, and others (6). Similarly, CML-suppressive CD4 ${ }^{+} \mathrm{T}$ cell clones, NK cells, and NKT cells were reported $(7,8)$. In contrast, we recently showed that PD-1/ $\mathrm{PD}-\mathrm{L} 1$ interaction and an impaired maturation of BCR/ABLexpressing DCs reduced the efficacy of the CTL response against CML $(9,10)$. Therefore, an activated immune system coexists over a prolonged time period with CML.

Authorship note: Christian Schürch and Carsten Riether contributed equally to this work.

Conflict of interest: The authors have declared that no conflict of interest exists. Citation for this article: J Clin Invest. 2012;122(2):624-638. doi:10.1172/JCI45977.
CD27 is a member of the TNF receptor family, which includes death domain-containing (DD-containing) proapoptotic receptors (TNF-R1, CD95/Fas, APO-3, TRAIL-R1/2) as well as receptors that control gene regulation, induce proliferation, and promote survival. These latter receptors have cytoplasmic residues that are bound by TNF receptor-associated factors (TRAFs) and include CD27, CD30, CD40, CD134/OX-40, and many others (11). The cytoplasmic domain of CD27 binds TRAF2, which signals downstream via

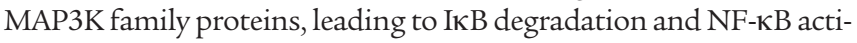
vation (12). TRAF2 can also activate JNK family members, bind to the inhibitor of apoptosis proteins (IAPs) and lead to upregulation of Bcl- $\mathrm{X}_{\mathrm{L}}$, an important antiapoptotic Bcl-2-like molecule $(13,14)$.

CD27 is expressed by subsets of T, B, and NK cells, and its role in the expansion and differentiation of effector $\mathrm{T}$ cells has been studied in detail (15). However, CD27 is also expressed on HSCs in $\mathrm{BM}$ (16), and CD27 signaling on HSCs and early BM progenitors provides a negative feedback signal toward leukocyte, especially $\mathrm{B}$ cell, differentiation (17).

The unique ligand of CD27 is the type II transmembrane glycoprotein CD70. CD70 expression is tightly controlled, and CD70 is only transiently expressed by mature DCs and activated lymphocytes during inflammatory processes (18). Persistent or prolonged expression of CD70 is found in chronic viral infections, autoimmune disorders, and some solid tumors and lymphomas (19).

Given the indications for an activated immune system in CML and the documented expression of CD27 on normal HSCs, we sought to analyze the expression of CD27 on LSCs with the aim of defining its function in leukemia. We used a retroviral transduction and transplantation model of BCR/ABL-induced CML-like disease in mice. CD27 was expressed by LSCs and 
leukemia progenitors, and the CD70-CD27 interaction promoted LSC proliferation and CML disease progression. Gene expression analysis and immunostainings of LSCs revealed that CD27 signaling induced the transcription of target genes of the canonical Wnt signaling pathway by enhancing the nuclear localization of active $\beta$-catenin and TRAF2- and NCK-interacting kinase (TNIK). As a consequence, blocking CD70 by mAb treatment reduced disease progression and prolonged survival of CML mice. Comparable to our results in the murine CML model, CD27 was expressed on $\mathrm{CD}^{+} 4^{+}$cells in BM of CML patients, and CD27 signaling in the human $\mathrm{BCR} / \mathrm{ABL}^{+}$leukemia cell line SD-1 activated the Wnt pathway and promoted cell proliferation.

\section{Results}

Leukemia stem and progenitor cells express CD27. CML was induced by retroviral transduction of C57BL/6 (BL/6) BM cells with BCR/ ABL-GFP, followed by transfer to irradiated (4.5 Gy) BL/ 6 recipient mice (WT CML) (9). HSCs and LSCs were defined as lineagenegative (lin $\left.{ }^{-}\right)$, Sca- $1^{+}$, and c-kit ${ }^{\text {hi }}(20)$; common myeloid progenitors (CMPs) were defined as lin $^{-}, \mathrm{Sca}-^{-}, \mathrm{c}-\mathrm{kit} \mathrm{t}^{\mathrm{hi}}, \mathrm{CD} 16 / 32^{-}$, and CD34lo; and granulocyte-macrophage progenitors (GMPs) as lin $^{-}$, Sca-1- ${ }^{-}, \mathrm{c}^{-k i t^{\mathrm{hi}}}$, CD $16 / 32^{+}$, and CD34hi (21). We first analyzed CD27 expression on LSCs, leukemia CMPs and GMPs, and differentiated granulocytes 20 days after transplantation. At this time point, WT CML mice had $62.8 \% \pm 1.5 \% \mathrm{BCR} / \mathrm{ABL}-\mathrm{GFP}^{+}$Ly6-G ${ }^{+}$granulocytes (of total granulocytes) in the peripheral blood. As a control, CD27 expression was similarly assessed on HSCs, CMPs, and GMPs of naive $\mathrm{BL} / 6$ mice. $\mathrm{CD} 27$ surface expression was detected by FACS on HSCs $(93.2 \% \pm 1.2 \%)$ and, interestingly, also on CMPs $(59.9 \%$ $\pm 4.1 \%)$ and GMPs $(87.0 \% \pm 2.1 \%)$ (Figure $1 \mathrm{~A})$. In WT CML mice, CD27 was expressed on LSCs $(32.8 \% \pm 3.3 \%)$, leukemia CMPs $(10.4 \% \pm 2.7 \%)$, and leukemia GMPs $(30.5 \% \pm 5.5 \%)$ (Figure $1 \mathrm{~B})$. Mature granulocytes in the blood of naive $\mathrm{BL} / 6$ control mice and malignant granulocytes in WT CML mice did not express CD27 (Figure 1C). Thus, although CD27 is expressed on normal HSCs, CMPs and GMPs, and on their malignant counterparts, the fraction that expresses CD27 is substantially smaller in LSCs and malignant progenitors.

During immune activation, CD27 is shed from the cellular membrane after being triggered by its ligand, CD70 (12). To determine whether the reduced expression of CD27 by LSCs is due to ligation and shedding, we treated WT CML mice with CD70-blocking mAb FR70 or control IgG from rat serum. Blocking CD70-CD27 interactions in WT CML mice resulted in upregulation of CD27 expression on LSCs (Figure 1, D and E). In contrast, FR70 treatment of naive BL/6 mice did not increase CD27 expression on HSCs (Supplemental Figure 1; supplemental material available online with this article; doi:10.1172/JCI45977DS1).

The CD27 ligand CD70 is only transiently expressed on activated lymphocytes and dendritic cells during immune activation (12). In the BM of CML mice, CD70 mRNA expression was detectable mainly in $\mathrm{CD}^{+} \mathrm{T}$ cells and at lower levels in CD $11 \mathrm{c}^{+}$dendritic cells and $\mathrm{CD} 19^{+} \mathrm{B}$ cells. In contrast, BCR/ABL-GFP leukemia cells did not express significant amounts of CD70 (Figure 1F). Therefore, CD27 is expressed on LSCs and ligated by CD70 expressed on BMinfiltrating immune cells.

CD27 signaling promotes CML progression. To analyze the role of CD27 signaling in CML development, we retrovirally transduced $\mathrm{BM}$ from $\mathrm{BL} / 6$ and $\mathrm{Cd} 27^{-/-}$mice with $\mathrm{BCR} / \mathrm{ABL}-\mathrm{GFP}$ before transfer into irradiated ( $4.5 \mathrm{~Gy}$ ) BL/6 recipient mice (Figure $2 \mathrm{~A}$ ).
As shown before, at this reduced irradiation dose, the adaptive immune system, including $\mathrm{CD}^{+} \mathrm{T}$ cells, $\mathrm{CD} 4^{+} \mathrm{T}$ cells, and $\mathrm{B}$ cells, originates from the recipient mouse (10). Therefore, this experimental setup allows generating CML from $C d 27^{-/-} \mathrm{BM}$ cells in a host with a CD27-competent immune system (Cd27-/- CML). Thus, CD27 expression on lymphocytes was similar in $\mathrm{Cd} 27^{-/-}$and WT CML mice (Supplemental Figure 2).

Even though the $C d 27^{-1-}$ mice are on a BL/6 background (22), we wanted to exclude small differences in the HSC compartment between both mouse strains. Subdifferentiation of LSK cells by FACS revealed no significant differences in absolute numbers of CD34-Flk2- ${ }^{-}$SK cells or CD34 ${ }^{+} \mathrm{Flk} 2^{-}$LSK cells between naive BL/6 and $C d 27^{-/-}$mice (Supplemental Figure 3).

$\mathrm{BCR} / \mathrm{ABL}-\mathrm{GFP}$ transduction efficacy was controlled in each experiment at the time point of transplantation. FACS analysis of $\mathrm{Cd} 27^{-/-}$and $\mathrm{BL} / 6 \mathrm{BM}$ cells that were cultured in vitro revealed similar GFP expression and therefore similar retroviral transduction rates. Furthermore, transduced $\mathrm{BL} / 6$ and $C d 27^{-/-} \mathrm{BM}$ cells formed equal numbers of $\mathrm{BCR} / \mathrm{ABL}-\mathrm{GFP}^{+}$colonies in methylcellulose (Supplemental Figure 4). In addition, we controlled the clonal development of the CML 20 days after transplantation in spleens of WT and Cd27-/- CML mice. Real-time PCR of genomic DNA revealed comparable contents of human c-abl, indicating similar proviral integration of the $\mathrm{BCR} / \mathrm{ABL}$ oncogene (Figure $2 \mathrm{~B}$ ). We also determined the expression of the oncogene $\mathrm{BCR} / \mathrm{ABL}$ on the mRNA level in WT and $C d 27^{-1-}$ LSCs using quantitative real-time RT-PCR for human c-abl. We found no significant differences in oncogene expression in WT or Cd27- $7^{--}$LSCs (Figure 2C). Similarly, MFI of BCR/ABL-GFP in lin- BM cells from WT and Cd27-/- CML mice were identical (Figure 2D). Thus, we conclude that WT and Cd27-/- LSCs and leukemia progenitors have a similar integration of human BCR/ABL in the genome and express similar amounts of BCR/ABL.

We next tested the homing capacity of retrovirally transduced $\mathrm{BL} / 6$ and $\mathrm{Cd} 27^{-/-} \mathrm{BM}$ cells to the $\mathrm{BM}$ of $\mathrm{BL} / 6$ recipient mice in vivo. The numbers of lin $^{-} \mathrm{BCR} / \mathrm{ABL}-\mathrm{GFP}^{+}$cells, BCR/ABL-GFP ${ }^{+} \mathrm{LSCs}$, and $\mathrm{BCR} / \mathrm{ABL}-\mathrm{GFP}^{+}$colony-forming cells isolated from $\mathrm{BM} 3$ days after transfer were comparable (Supplemental Figure 5).

Blood smears, cytospins, and FACS analysis of granulocyte differentiation markers revealed that granulocytes from WT and Cd27-1- CML mice were comparably differentiated and mature (Figure 2E and Supplemental Figure 6). Twelve days after transplantation, WT and $C d 27^{-1-}$ CML mice had similar numbers of $\mathrm{BCR} / \mathrm{ABL}-\mathrm{GFP}^{+}$granulocytes in the circulation, confirming similar engraftment of the malignant progenitor cells (Figure 2F). In contrast, progression of WT CML was significantly faster when compared with $C d 27^{-/-} \mathrm{CML}$, resulting in higher BCR/ABL-GFP ${ }^{+}$ granulocyte counts in the blood at later stages of the disease (Figure $2 \mathrm{~F}$ and data not shown). WT CML mice all died because of leukemia within 40 days after transplantation $(9,10)$, whereas leukemia development was delayed in $\mathrm{Cd} 27^{-/-} \mathrm{CML}$ animals and $25 \%$ of them survived up to 80 days after transplantation without overt leukemia, as analyzed by determination of peripheral blood granulocyte counts (Figure $2 \mathrm{G}$ and data not shown). CML mice died with classical symptoms of CML, such as high leukocyte counts (Figure 2F), enlarged spleens (Supplemental Figure 7A), pulmonary hemorrhage, and granulocyte infiltrations in different organs. The prolonged survival of $C d 27^{-/-} \mathrm{CML}$ mice could not be attributed to differences in CD27 signaling to host T cells because BCR/ABL-GFP-transduced BL/6 BM cells induced 

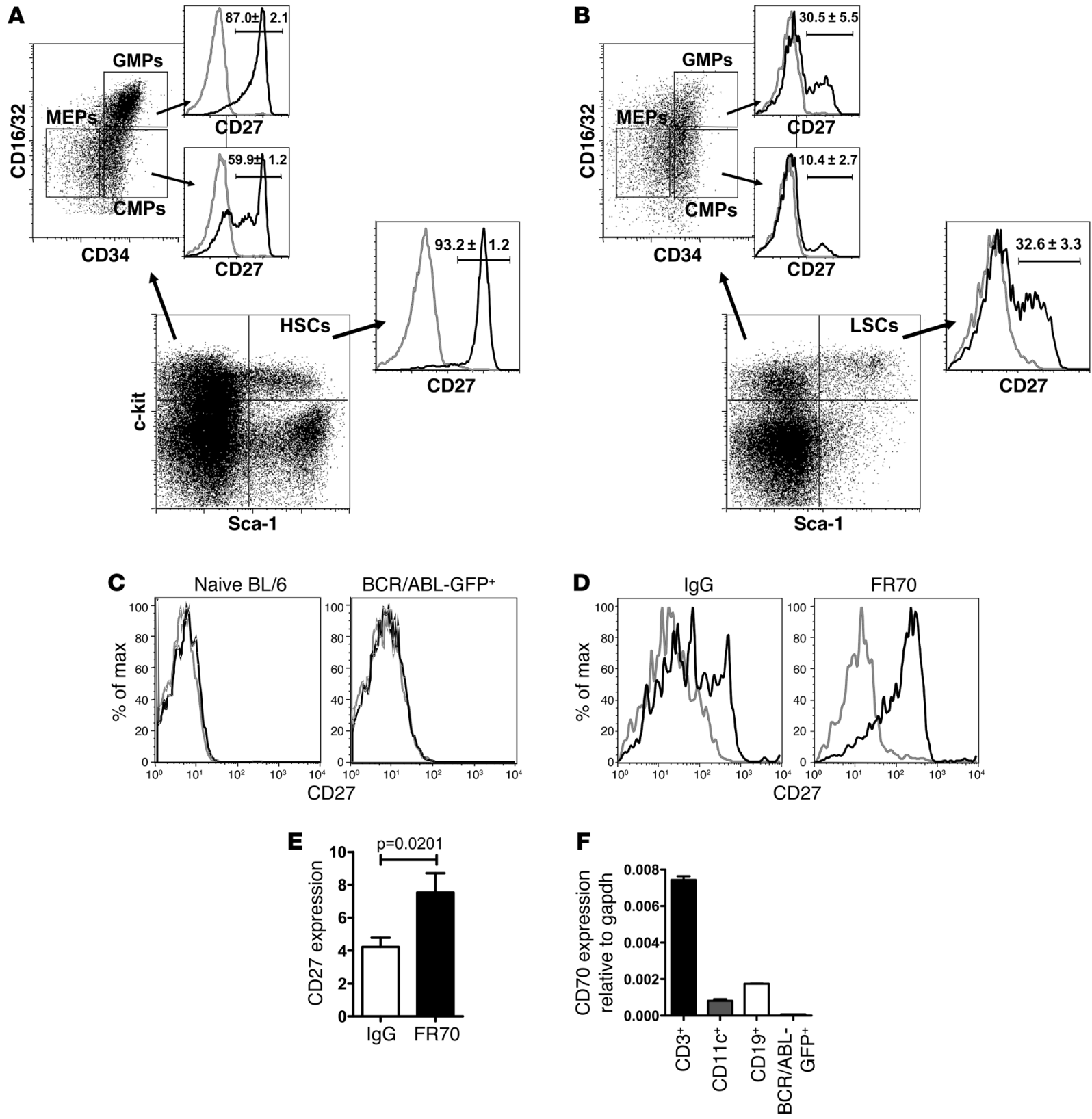

\section{Figure 1}

CML stem and progenitor cells express CD27. (A) Expression of CD27 on naive BL/6 HSCs and myeloid lineage progenitors. One representative plot of 3 is shown. (B) Expression of CD27 on LSCs and myelogenous leukemia progenitors in WT CML. One representative plot of 5 is shown. (C) FACS analysis of CD27 on Ly6-G+ granulocytes in blood of naive BL/6 mice and BCR/ABL-GFP+ Ly6-G+ granulocytes in WT CML mice. 1 representative plot of $2-3$ is shown. (D) WT CML animals were either treated with $300 \mu \mathrm{g} \operatorname{lgG}$ from rat serum $(n=10)$ or $300 \mu \mathrm{g}$ FR70 $(n=16)$ i.p., and CD27 was stained on LSCs after 12 hours. 1 representative histogram per group is shown. (E) CD27 expression on LSCs was calculated as MFI CD27 staining/MFI isotype staining for each sample. Pooled data from 3 independent experiments are shown. (F) $C D 70$ mRNA expression in cell subsets in BM cells pooled from WT CML mice. 1 representative of 2 experiments with $n=5-7$ mice is shown. Data are displayed as mean \pm SEM. Statistics: Student's $t$ test with Welch's correction. Gray lines, isotype controls; black lines, CD27 stainings. MEPs, megakaryocyte-erythrocyte progenitors.

leukemias with similar kinetics in $\mathrm{BL} / 6$ and $\mathrm{Cd} 27^{-1-}$ hosts (Supplemental Figure 8). Therefore, CD27 signaling on LSCs and CML progenitors promotes leukemia progression.

Characterization of LSCs and myelogenous leukemia progenitor cells. In a next step, we wanted to characterize LSCs and leukemia progenitors in WT and $C d 27^{-/-}$CML animals in more detail. Fifteen days after transplantation, LSC numbers in WT and Cd27-1CML mice were similar. However, 20 days after transplantation, LSC numbers in WT CML mice were significantly higher than in $C d 27^{-/-}$CML mice (Figure $2 \mathrm{H}$ ). Likewise, analysis of lin $^{-}$ 

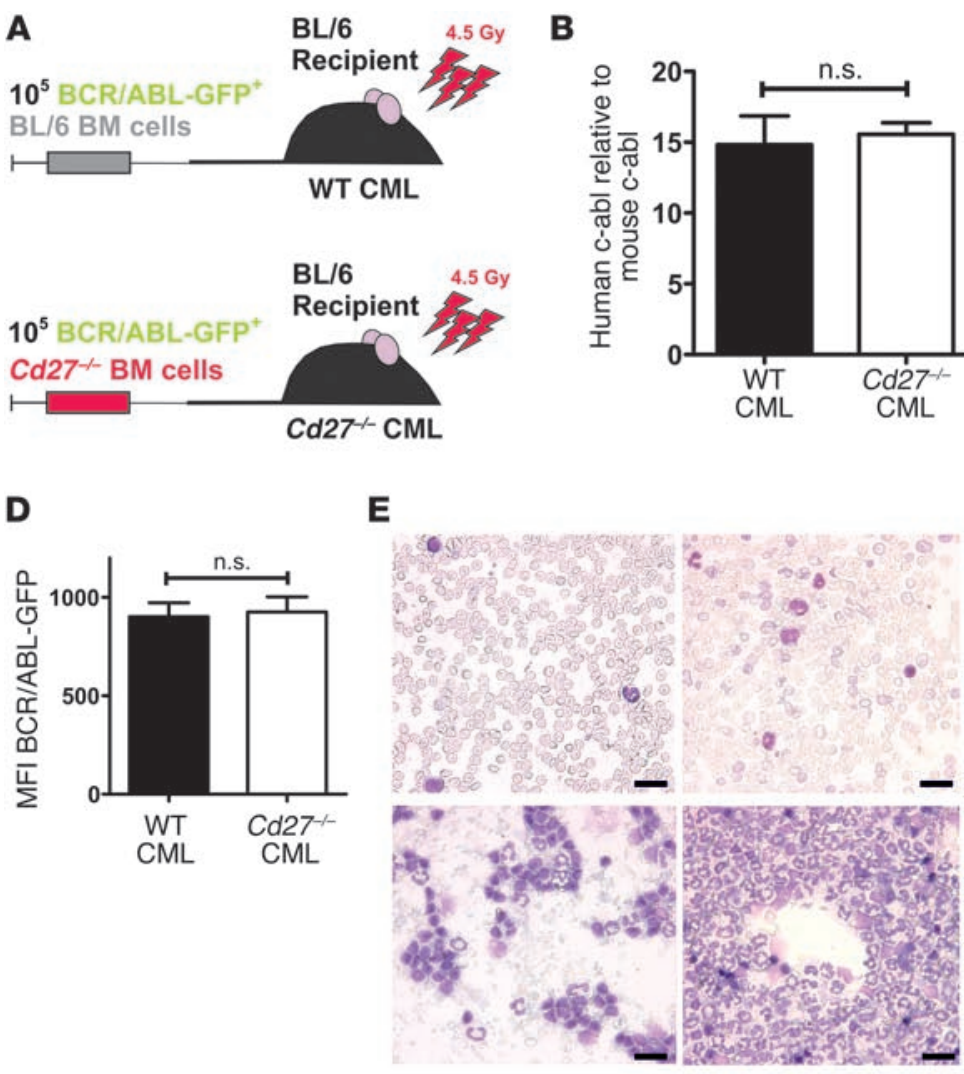

H

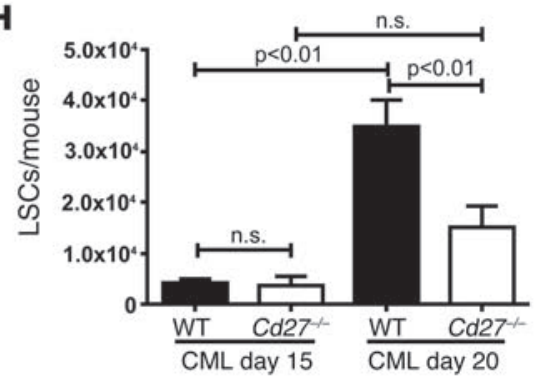

B

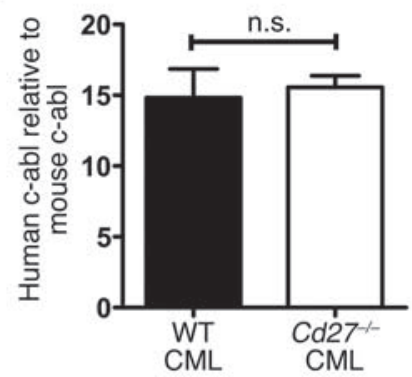

E

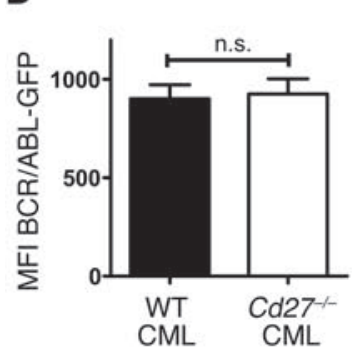

Naive BL/6

D

WT CML
C

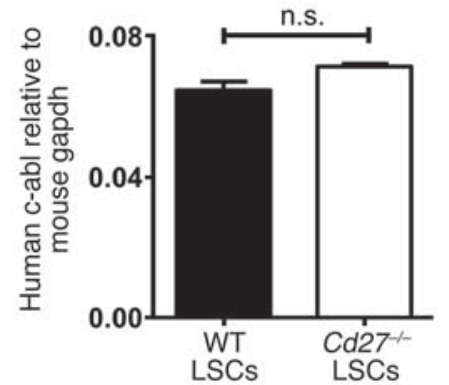

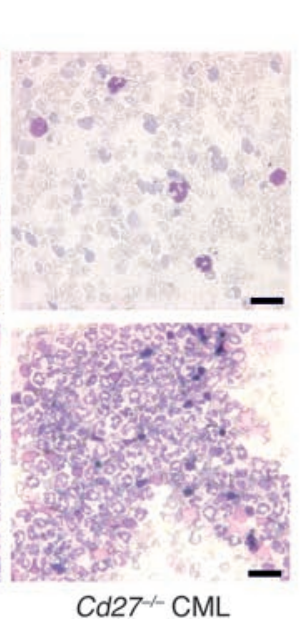

F

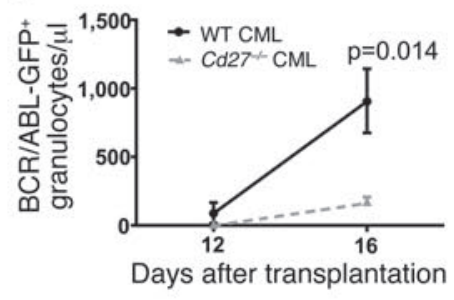

G

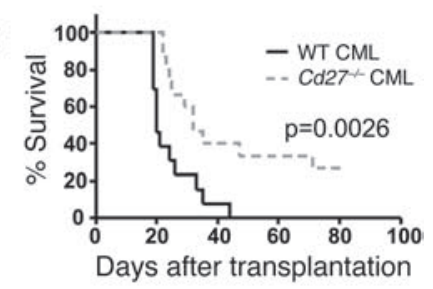

I

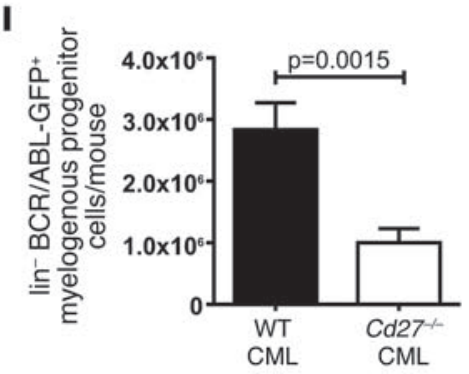

Figure 2

CD27 signaling promotes CML progression. (A) Experimental model. (B) Genomic DNA was isolated from spleens of WT $(n=5)$ and $C d 27^{-/-}$ $(n=3) \mathrm{CML}$ mice and analyzed by real-time PCR. $\Delta \Delta \mathrm{C}_{\mathrm{t}}$ values of human c-abl were normalized to $\Delta \Delta \mathrm{C}_{\mathrm{t}}$ values of murine $\mathrm{C}$-abl. (C) Expression of human c-abl mRNA in FACS-purified, pooled LSCs from WT $(n=19)$ and Cd27-l- $(n=21) \mathrm{CML}$ mice 20 days after transplantation. (D) Expression of BCR/ABL-GFP in lin- BM cells of WT $(n=37)$ and Cd27-/- $(n=45)$ CML mice (pooled data from 7 independent experiments). (E) Blood smears (upper row) and cytospins (lower row) of naive BL/6, WT CML, and Cd27-/- CML mice. Scale bars: $20 \mu \mathrm{m}$. (F) Numbers of BCR/ABL-GFP+ granulocytes/ $\mu$ l blood ( $n=8$ mice per group) and (G) Kaplan-Meier survival curves resulting from primary transplantations of BCR/ABL-GFP-transduced $\mathrm{BL} / 6$ (black line, $n=13$ ) versus Cd27-/- (dotted line, $n=15$ ) BM cells into BL/6 recipients (pooled data from 2 independent experiments). (H) LSC numbers per mouse 15 days ( $n=5$ mice per group) and 20 days ( $n=15$ mice per group) after transplantation. (I) Numbers of lin-, BCR/ABL-GFP+ cells per mouse 20 days after transplantation ( $n=15$ mice per group). Data are displayed as mean \pm SEM. Statistics: Student's $t$ test (B-D, I), 2-way ANOVA (F), log-rank test $(\mathbf{G})$, and 1-way ANOVA $(\mathbf{H})$. Cells/mouse = cells from both femora, tibiae, and humeri.

BCR/ABL-GFP ${ }^{+}$cells, lin ${ }^{-}$c-kit ${ }^{\text {hi }}$ BCR/ABL-GFP ${ }^{+}$cells, BCR/ABL$\mathrm{GFP}^{+} \mathrm{CMPs}$, and GMPs revealed that CD27 signaling led to an increase in these myelogenous leukemia progenitor cell types (Figure 2I and Supplemental Figure 7, B-D).

CD27 signaling enhances proliferation and cell cycle progression of LSCs. CD27 signaling on lymphocytes enhances proliferation and induces antiapoptotic molecules (12). So far, however, the question as to whether this also holds true for LSCs has not been addressed. Therefore, we compared proliferation and cell cycle progression of FACS-sorted LSCs from WT and $\mathrm{C} d 27^{-/-}$CML mice. Approximately $6 \%-7 \%$ of HSCs from naive $\mathrm{BL} / 6$ and $\mathrm{Cd} 27^{-/-}$mice incorporated BrdU (Figure 3A). This is in agreement with published data indicating that a small fraction of HSCs undergoes cell cycling (23). In contrast, BrdU incorporation in WT LSCs was approximately 
A
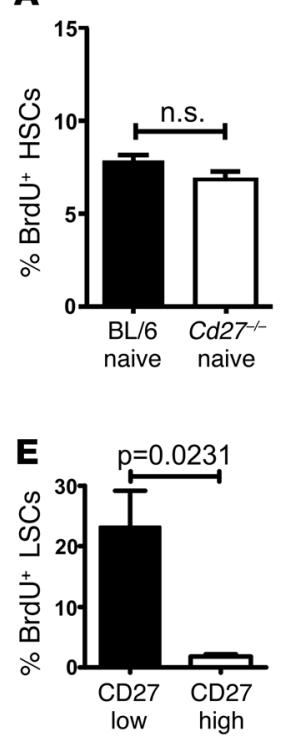

B

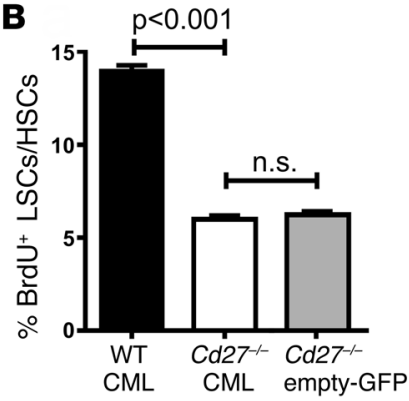

C

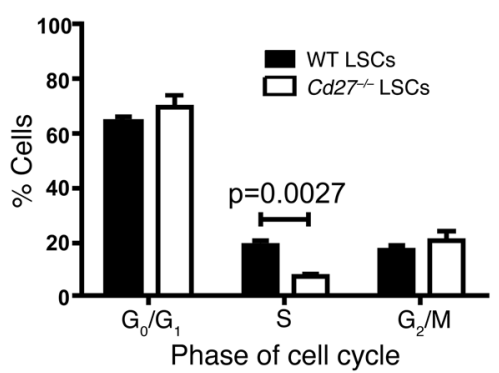

D

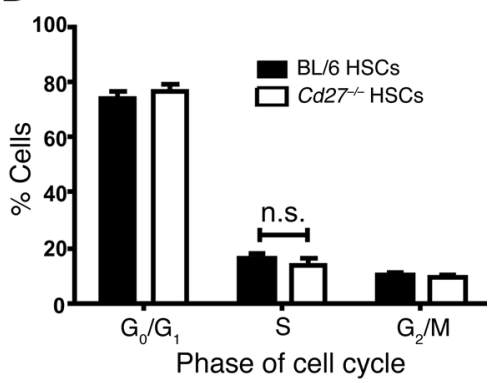

F

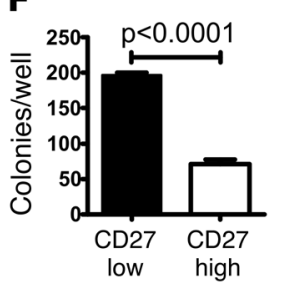

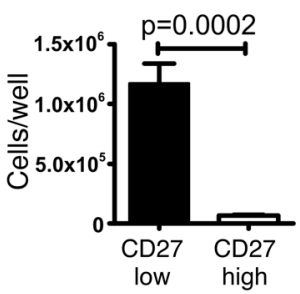

G

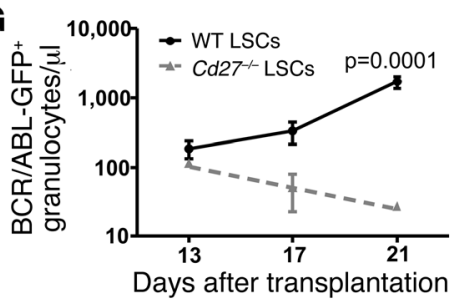

H

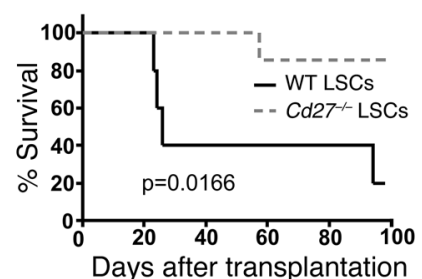

1 㕝.

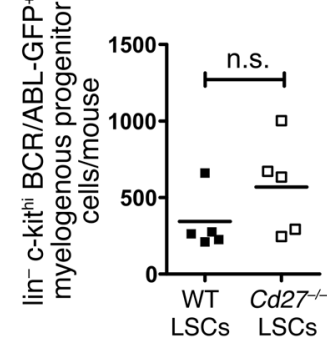

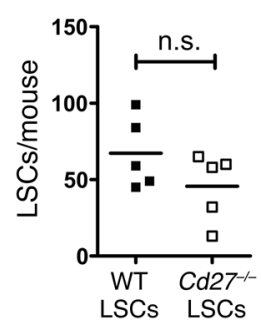

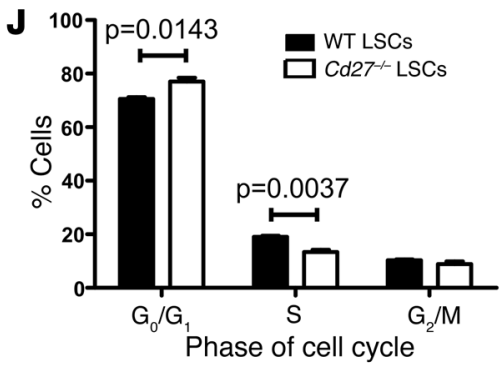

Figure 3

CD27 signaling enhances proliferation and cell cycle progression of LSCs in vivo. (A and B) Analysis of (A) naive HSC and (B) LSC proliferation by BrdU incorporation. Empty GFP-transduced naive Cd27-- HSCs were used as a control in B. (C and D) Cell cycle analysis by DAPI stainings of (C) LSCs and (D) naive HSCs. Cells of $n=3-8$ animals per group were pooled in each experiment. Pooled data from 4 independent experiments are shown. (E) LSCs pooled from 6 WT CML mice were separated by FACS sorting based on surface expression of CD27 (lo or hi), and BrdU incorporation was analyzed by FACS. (F) $10^{3}$ FACS-purified, CD27 lo- or hi-expressing WT LSCs were plated into methylcellulose, and colonies and cells per well were enumerated 7 days later. (G-J) $2 \times 10^{4}$ LSCs from WT or Cd27-- CML animals were isolated by FACS 20 days after primary transplantation and secondarily transplanted into irradiated (4.5 Gy) BL/6 recipients. (G) Granulocyte counts/ $\mu$ blood $(n=3$ mice per group) and (H) Kaplan-Meier survival curves resulting from secondary transplantations of WT (black line, $n=5$ ) or Cd27-/- (dotted line, $n=7$ ) LSCs (pooled data from 2 independent experiments). (I) Lin- c-kithi BCR/ABL-GFP+ myelogenous progenitor cell numbers and LSC numbers per mouse in the BM of BL/6 recipients 4 days after secondary transplantation. (J) Cell cycle analysis by DAPI stainings of LSCs in secondary CML 20 days after transplantation. BrdU incorporation was calculated as the difference in the percentage of $\alpha-\mathrm{BrdU}^{-\mathrm{PE}^{+}}$minus isotype control-PE ${ }^{+}$ cells. Data are displayed as mean \pm SEM. Statistics: Student's $t$ test $(\mathbf{A}-\mathbf{F}, \mathbf{I}$, and $\mathbf{J}), 2$-way ANOVA $(\mathbf{G})$, and log-rank test $(\mathbf{H})$. Cells/mouse $=$ cells from both femora, tibiae, and humeri.

3-fold higher than in Cd27-/- LSCs (Figure 3B). There were no significant differences in BrdU incorporation among $\mathrm{Cd} 27^{-/-}$LSCs and empty GFP vector-transduced $C d 27^{-/-}$HSCs or naive BL/ 6 or $C d 27^{-1-}$ HSCs (Figure 3B and data not shown). In addition, we performed an analysis of the cell cycle status using DAPI staining. The fraction of WT LSCs in S phase was approximately 2-fold higher than that of $C d 27^{-1-}$ LSCs (Figure 3C). Again, no significant differences were observed in the cell cycle status of naive control HSCs (Figure 3D). Analysis of LSC viability using 7-aminoactinomycin $\mathrm{D}$ (7-AAD) and annexin $\mathrm{V}$ did not reveal significant differences between WT and Cd27-/- CML animals (Supplemental Figure 9).

As depicted in Figure 1B, LSCs in WT CML consist of a population of CD27hi LSCs and, due to ligation with CD70 (Figure 1, D and $\mathrm{E}$ ), a population of $\mathrm{CD} 27^{\text {lo }} \mathrm{LSC}$. Isolation of these 2 popula- tions allowed us to study the effect of CD27 ligation on LSCs in vivo. Functional analysis of FACS-sorted CD27hi and CD27lo LSCs from WT CML animals revealed that BrdU incorporation in CD27lo LSCs was greatly increased (Figure 3E). In addition, FACS-sorted CD27lo LSCs formed significantly more colonies and cells in methylcellulose than CD27 hi LSCs (Figure 3F).

Taken together, these observations indicate that CD27 signaling on LSCs increases LSC proliferation.

CD27 signaling promotes leukemia progression in secondary CML. Transduction of BM with BCR/ABL-GFP retroviral particles may lead to integration in HSCs but also in progenitor cells. To compare CML development after transplantation of identical numbers of LSCs, $2 \times 10^{4}$ LSCs from WT or Cd27-/- CML were isolated by FACS 20 days after primary transplantation and 

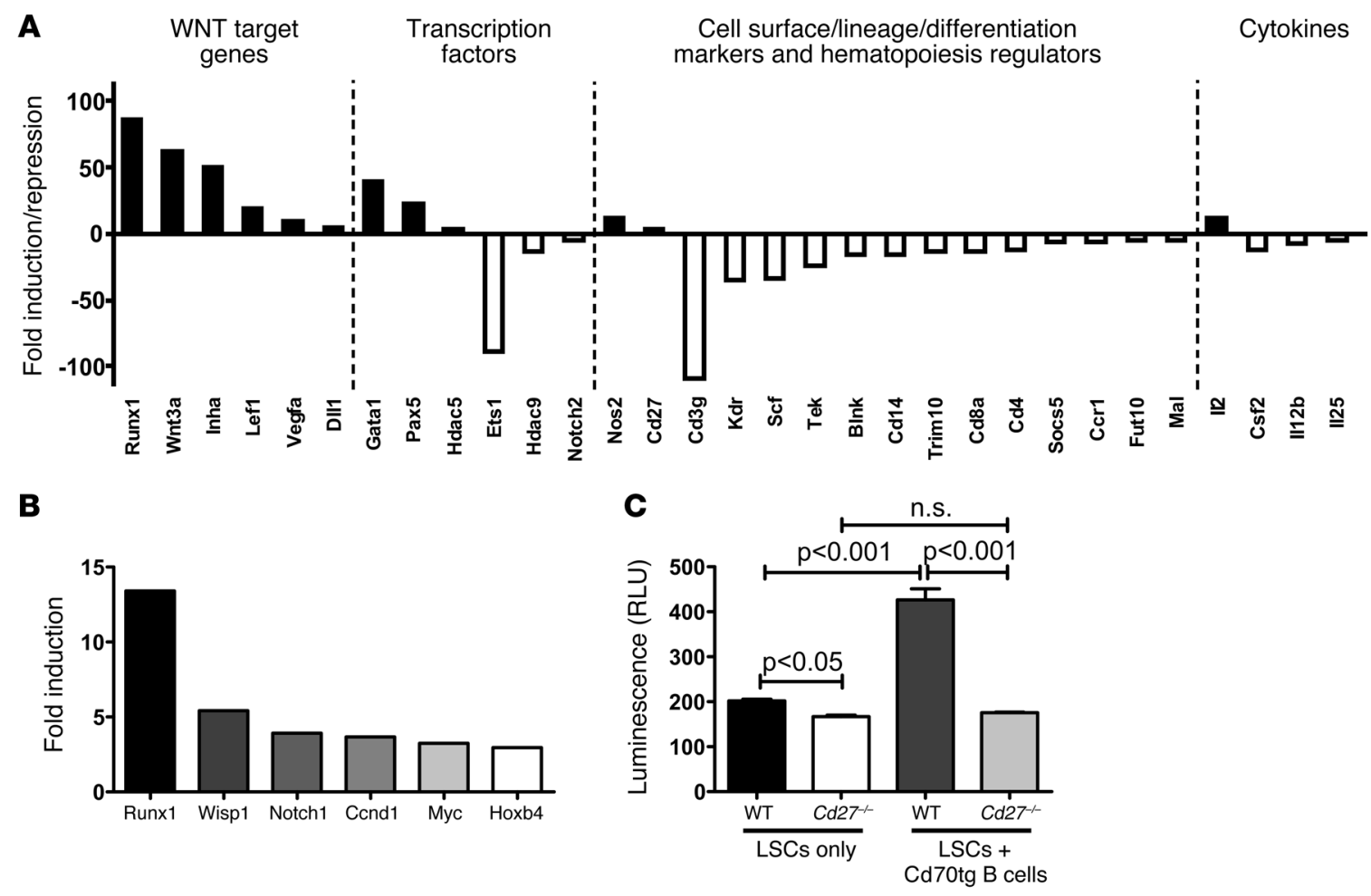

\section{Figure 4}

CD27 signaling enhances Wnt signaling in LSCs. (A) Real-time RT-PCR array of hematopoietic genes in LSCs sorted and pooled from WT CML mice $(n=8)$ compared with $C d 27^{-/} \mathrm{CML}$ mice $(n=8)$. Only genes that displayed a 4-fold or greater change are shown. (B) Quantitative real-time RT-PCR of selected Wnt target genes in pooled LSCs from WT $(n=19)$ versus Cd27-l- $(n=21)$ CML mice. (C) Tcf/Lef luciferase reporter assay of pooled LSCs from WT and Cd27-/- CML mice ( $n=5$ animals per group). Data are displayed as mean \pm SEM. Statistics: 1 -way ANOVA.

injected into irradiated $(4.5 \mathrm{~Gy})$ secondary BL/6 recipients. WT LSCs regularly induced CML in secondary recipients, whereas CD27-deficient LSCs failed to effectively establish CML (Figure 3, G and H). A genomic real-time PCR of secondary recipients indicated a similar integration of the BCR/ABL oncogene (Supplemental Figure 10). To exclude a potential role of CD27 on LSC homing, we assessed the numbers of myelogenous leukemia progenitors and LSCs in the BM after secondary transplantation into irradiated $\mathrm{BL} / 6$ mice. There was no significant difference in the numbers of $\mathrm{lin}^{-}, \mathrm{c}-\mathrm{kit} \mathrm{t}^{\mathrm{hi}}, \mathrm{BCR} / \mathrm{ABL}-\mathrm{GFP}^{+}$progenitor cells or LSCs in secondary hosts 4 days after transplantation of $2 \times 10^{4}$ purified WT or Cd27-/- LSCs (Figure 3I).

In analogy to primary CML, we analyzed LSC proliferation in secondary CML by DAPI staining 20 days after secondary LSC transplantation. Secondary WT LSCs proliferated significantly more than secondary $\mathrm{Cd} 27^{-/-}$LSCs (Figure 3J), further confirming that CD27 signaling induces LSC proliferation.

CD27 signaling enhances Wnt signaling in LSCs. To dissect the mechanism of CD27 signaling on LSCs, we first analyzed a hematopoiesisspecific gene expression profile of WT and Cd27-/- LSCs. FACS sorting of LSCs resulted in approximately $1 \times 10^{4}$ LSCs per CML mouse. Therefore, to reach sufficient cell numbers for gene expression profiling, FACS-sorted LSCs from 8 CML mice per group were pooled for this experiment. Using an $\mathrm{RT}^{2}$ Profiler PCR Array, we assessed 84 genes related to hematopoiesis. CD27 signaling induced the expression of 12 genes and repressed 19 genes in LSCs (Figure 4A and Supplemental Table 1). Interestingly, target genes of the canonical Wnt pathway, i.e., Runx1, Wnt3a, Inha, Lef1, Vegfa, and Dll1, were strongly upregulated. In addition, genes involved in cell cycle transition (Pax5, Hdac5) and HSC differentiation (Gata1) were upregulated by CD27 signaling. In contrast, genes involved in HSC quiescence (Tek/Tie2) and in normal blood cell development and differentiation $(C d 3 g, C d 4, C d 8 a, C d 14, B \ln k)$ were downregulated.

To further confirm and extend the results from the PCR array, we investigated the expression of additional Wnt target genes in FACS-sorted WT versus Cd27-/- LSCs by real-time RT-PCR. Using Runx 1 as a positive control, we found that the expression of Wnt target genes Wisp1, Notch1, Ccnd1, Myc, and Hoxb4 was at least 3 -fold higher in WT than in Cd27-/- LSCs (Figure 4B). In addition, we performed a lentivirus-based $\mathrm{T}$ cell transcription factor/lymphoid enhancer factor (Tcf/Lef) reporter luciferase assay to measure activation of the Wnt pathway in FACS-purified WT and Cd27-/- LSCs (Figure 4C). The Wnt pathway was more activated in WT than in $C d 27^{-1-}$ LSCs. To provide extra CD27 ligation in vitro, purified B cells isolated from $\mathrm{Cd} 70 \mathrm{Tg}$ (Cd70-Tg) mice that constitutively express CD70 under the control of the CD19 promoter were added to the purified LSCs. Additional CD27 stimulation profoundly increased activation of the Wnt pathway in WT LSCs, whereas no effect could be observed in $C d 27^{-/-}$LSCs (Figure 4C).

In summary, these findings indicate that triggering CD27 on LSCs activates the Wnt pathway.

CD27 signaling increases nuclear localization of active $\beta$-catenin in LSCs. Activated $\beta$-catenin is the key mediator of the Wnt signaling pathway (24). In CML, $\beta$-catenin is constantly active by 

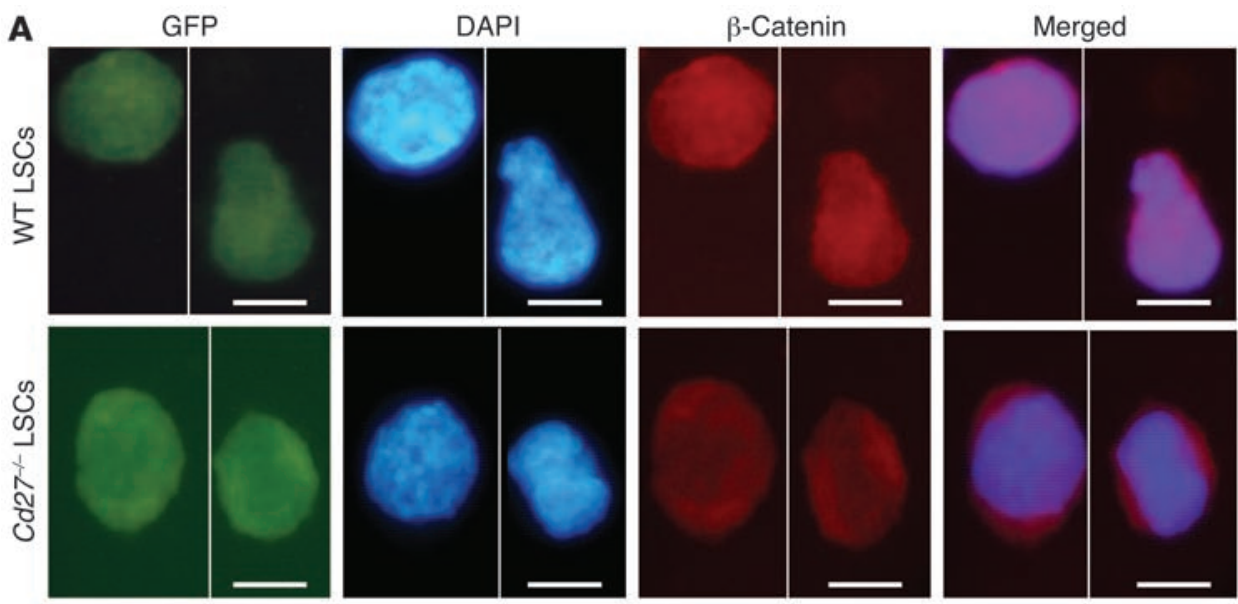

D
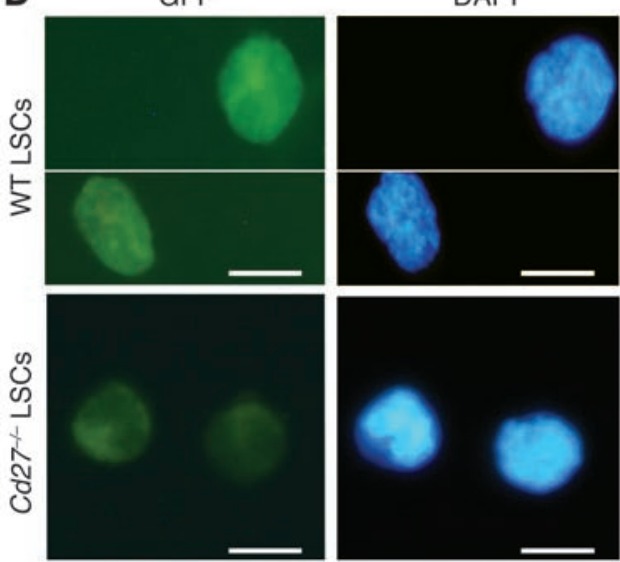

TNIK
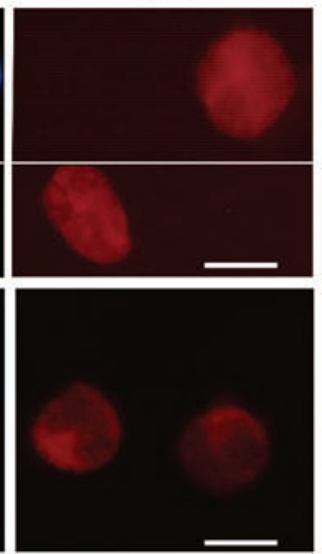

Merged

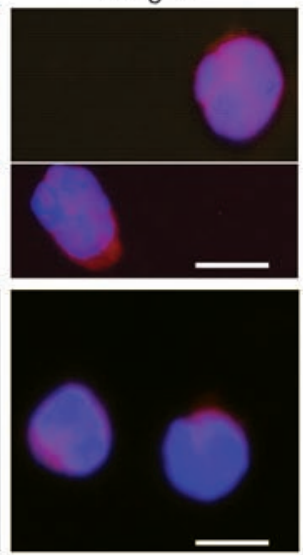

B

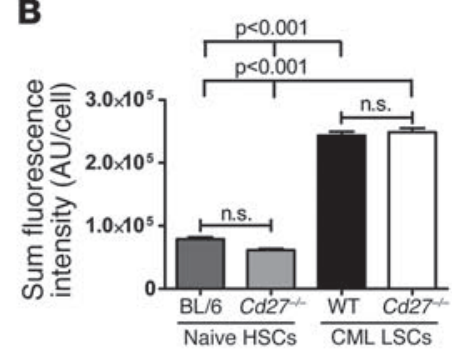

C

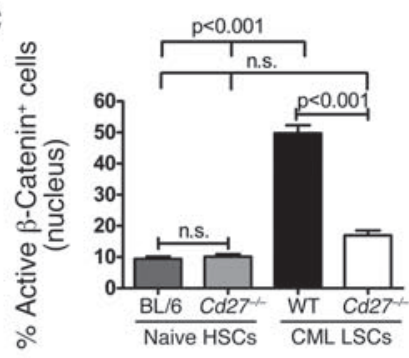

E

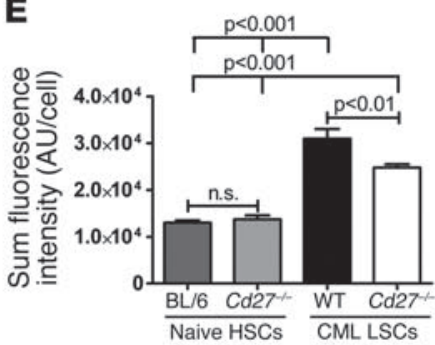

$\mathbf{F}$

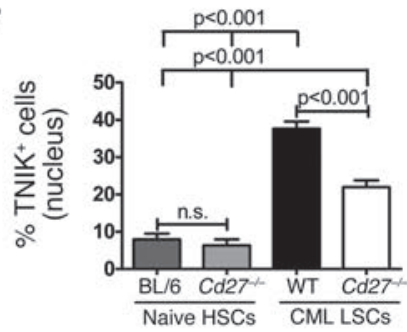

Figure 5

CD27 signaling increases nuclear localization of active $\beta$-catenin and TNIK in LSCs. (A) Immunostainings for active $\beta$-catenin in LSCs from WT and $\mathrm{Cd} 27^{-/-} \mathrm{CML}$ mice. GFP, DAPI, $\beta$-catenin, and the merging of DAPI and $\beta$-catenin are shown. Scale bars: $5 \mu \mathrm{m}$. (B) SFI of active $\beta$-catenin in naive HSCs and CML LSCs. (C) Percentage of naive HSCs and CML LSCs positive for nuclear active $\beta$-catenin. (A-C) 90-460 cells were analyzed. (D) Immunostainings for TNIK in LSCs from WT and Cd27-/- CML mice. GFP, DAPI, TNIK, and the merging of DAPI and TNIK are shown. Scale bars: $10 \mu \mathrm{m}$. (E) SFI of TNIK in naive HSCs and CML LSCs. (F) Percentage of naive HSCs and CML LSCs positive for nuclear TNIK. (D-F) 47-528 cells were analyzed. (A and D) For clarity, cells in some images were spliced together from the same microscopic field of view. Data are displayed as mean \pm SEM. Statistics: 1 -way ANOVA.

BCR/ABL-mediated tyrosine phosphorylation (25). We analyzed the expression and localization of active $\beta$-catenin by immunofluorescence stainings of FACS-sorted LSCs (Figure 5, A-C). Sum fluorescence intensity (SFI) of active $\beta$-catenin was similar in naive $\mathrm{BL} / 6$ and $C d 27^{-/-}$HSCs. In contrast, the SFI of active $\beta$-catenin was significantly higher in LSCs than in HSCs. However, no difference in SFI was observed between WT and $C d 27^{-1-}$ LSCs, indicating a similar expression of active $\beta$-catenin independently of CD27 signaling (Figure 5B). Interestingly, active $\beta$-catenin was preferentially localized in the nucleus in LSCs with intact CD27 signaling, whereas only a minority of normal HSCs or $C d 27^{-/-}$LSCs expressed $\beta$-catenin in the nucle- us (Figure 5C). These data provide evidence that CD27 signaling on LSCs increases nuclear translocation of active $\beta$-catenin, a key step in the transcription of Wnt target genes.

CD27 signaling increases nuclear localization of TNIK in LSCs. TNIK interacts with TRAF2, an important scaffold protein involved in CD27 signaling (26) and is a fundamental activator of Tcf4/ $\beta$-catenin-mediated Wnt target gene transcription $(27,28)$. However, whether TNIK is expressed and functional in HSCs or LSCs has not been analyzed so far. We found TNIK expression on the protein level by immunofluorescence (Figure 5D) and on the mRNA level by quantitative real-time RT-PCR (Supplemental Figure 11). TNIK SFI was significantly higher in WT than in 
A

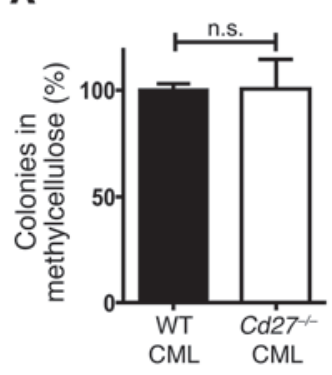

B

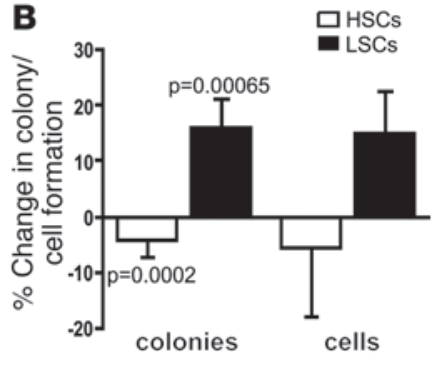

C

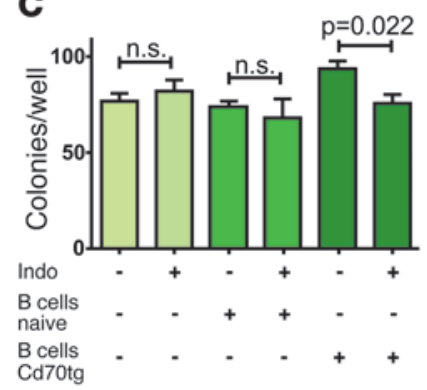

D

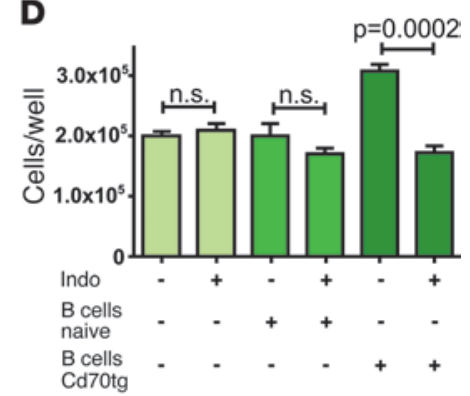

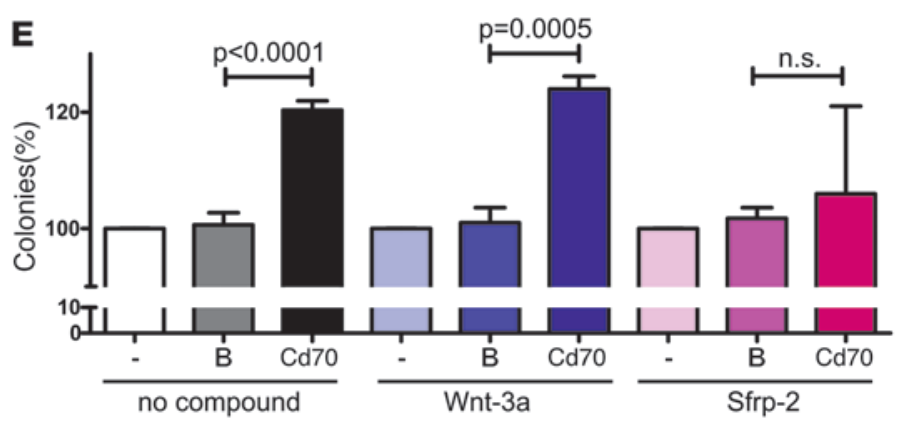

Figure 6

CD27 signaling increases the colony formation of LSCs in a Wnt/ $\beta$-catenin-dependent manner. (A) $10^{3}$ FACS-purified LSCs from WT or Cd27-/CML mice were directly plated in methylcellulose, and colonies were enumerated 7 days later. Pooled data from 2 independent experiments each run in triplicate are shown. Values of colonies are shown in relation to the mean of WT LSCs $(=100 \%)$. (B) $5 \times 10^{3}$ FACS-purified GFP- HSCs $(n=7)$ or BCR/ABL-GFP+ LSCs $(n=8)$ from individual WT CML mice were incubated overnight with $5 \times 10^{4}$ irradiated (10 Gy) naive BL/6 or Cd70tg CD19+ B cells, followed by plating in methylcellulose. Colonies and total cells were enumerated after 7 days. Data illustrate the percentage change in colony or cell formation of naive BL/6 CD19+ versus CD70-Tg CD19+ coincubations in each individual WT CML sample (naive $\left.\mathrm{BL} / 6 \mathrm{CD} 19^{+}=100 \%\right)$. Pooled results of 3 independently performed experiments are shown. $(\mathrm{C}-\mathrm{E}) 5 \times 10^{3} \mathrm{FACS}-$ purified LSCs from pooled WT CML mice were incubated overnight with or without $5 \times 10^{4}$ irradiated (10 Gy) naive BL/6 or Cd70tg CD19+ $B$ cells in the presence or absence of (C and D) $60 \mu \mathrm{M}$ indomethacin or (E) $100 \mathrm{ng} / \mathrm{ml} \mathrm{Wnt-3a} \mathrm{or} 1 \mu \mathrm{g} / \mathrm{ml}$ Sfrp-2, followed by plating in methylcellulose ( \pm the respective compound). Numbers of colonies (C and $\mathbf{E}$ ) and cells (D) per well were assessed 7 days later. Each condition was run in quadruplicate to sextuplicate. Data are displayed as mean \pm SEM. Statistics: Student's $t$ test.

Cd27-/- LSCs. Additionally, TNIK was expressed at significantly higher levels in LSCs than in HSCs (Figure 5E). Nuclear TNIK expression was significantly higher in WT LSCs than in $C d 27^{-1-}$ LSCs, comparable to the preferential localization of active $\beta$-catenin in the nucleus in CD27-competent LSCs (Figure 5F). No difference in nuclear TNIK expression was observed in naive control HSCs. Therefore, CD27 signaling on LSCs increases nuclear translocation of the transcriptional activator TNIK.

CD27 signaling increases colony formation of LSCs in a Wnt/ß-catenindependent manner. LSCs were functionally analyzed in vitro for their capacity to form colonies in methylcellulose. FACS-purified LSCs from WT and $C d 27^{-/-}$CML mice isolated 20 days after transplantation formed equal numbers of colonies in methylcellulose (Figure 6A). To address the effect of CD70-mediated CD27 stimulation on LSCs directly, we sorted GFP- control HSCs and BCR/ABL-GFP ${ }^{+}$ LSCs from individual WT CML mice and incubated these cells in the presence of irradiated ( $10 \mathrm{~Gy}$ ) CD19+ $\mathrm{B}$ cells from either naive $\mathrm{BL} / 6$ mice or from Cd70tg mice. CD27 signaling on $\mathrm{GFP}^{-}$control HSCs decreased colony formation. In contrast, LSCs formed significantly more colonies after triggering CD27 (Figure 6B). The increase in the number of colonies was reflected by a parallel increase in the cell numbers isolated from the methylcellulose cultures after CD27 triggering (Figure 6B). These results indicate that, in contrast to normal HSCs, CD27 signaling on LSCs increases colony formation.
To determine whether active $\beta$-catenin is responsible for the observed increase in colony and cell numbers after CD27 triggering, we cultured CD27-stimulated LSCs in the presence or absence of the cyclooxygenase inhibitor indomethacin (29). Indomethacin enhances the degradation of active $\beta$-catenin by blocking PGE2 synthesis (30). Indomethacin did not affect colony formation and cell numbers without CD27 stimulation. However, indomethacin treatment significantly decreased colony formation and cell numbers after LSC coculture with Cd70tg CD19+ B cells (Figure 6, C and D).

In the next experiment, we analyzed the role of extracellular Wnt ligands on the CD27-mediated increase in LSC numbers. Additional stimulation of the Wnt pathway in WT LSCs by providing exogenous Wnt-3a did not further increase colony formation, regardless of CD27 stimulation (Figure 6E). In contrast, blocking extracellular Wnt ligands by addition of secreted frizzled-related protein 2 (Sfrp2), a soluble Wnt antagonist, completely inhibited the CD27-mediated increase in LSC colony formation (Figure 6E).

These results indicate that CD27-mediated LSC proliferation is mediated by the Wnt/ $\beta$-catenin pathway and is dependent on extracellular Wnt ligands.

Blocking CD70-CD27 interaction prolongs survival of WTCML mice. After having provided evidence that CD27 signaling on LSCs increases progression of CML, we next sought to analyze whether blocking the CD70-CD27 interaction by mAb treatment can be used to treat 
A

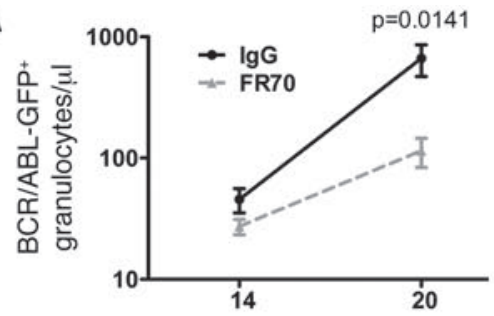

Days after transplantation

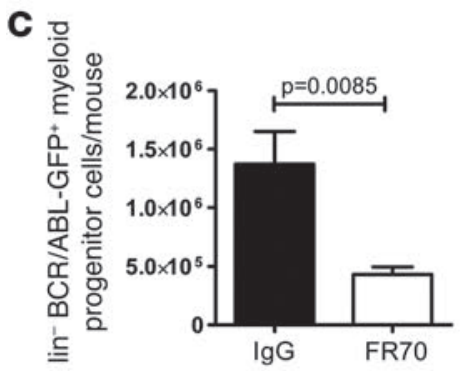

E
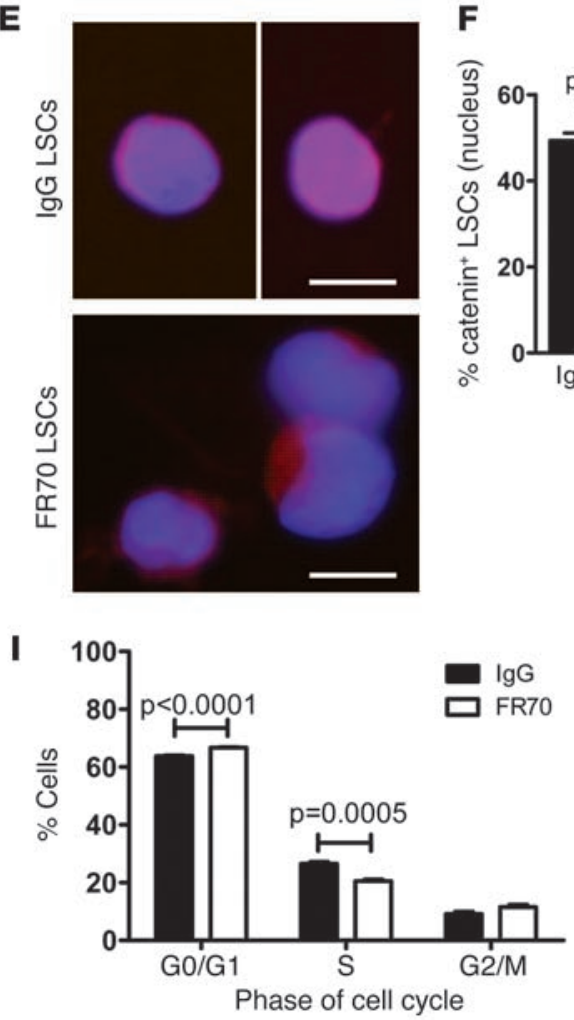

B

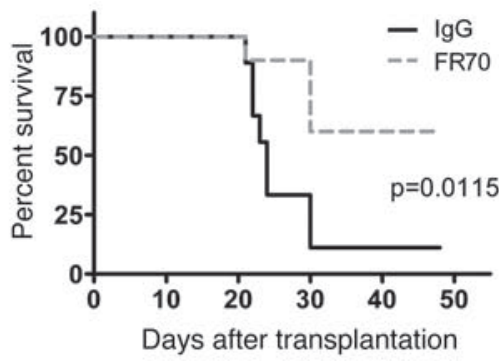

D

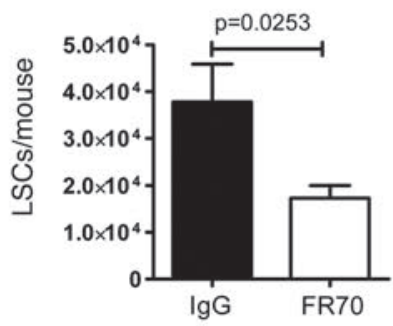

F G
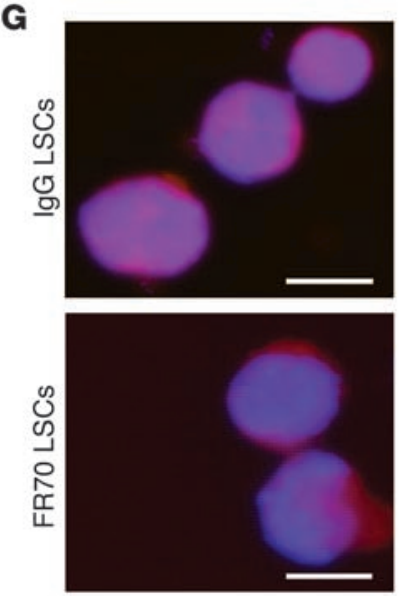

H

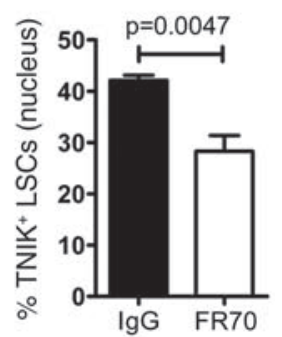

$\mathbf{J}$

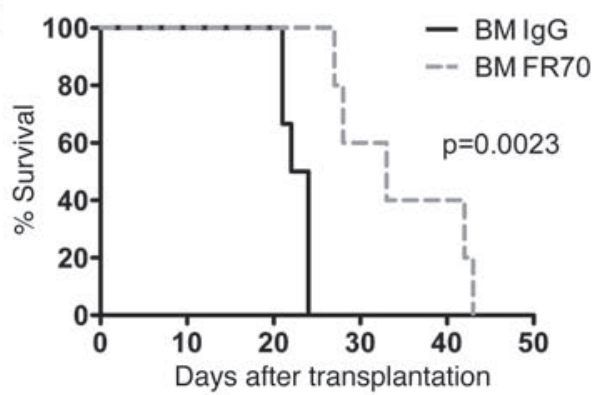

\section{Figure 7}

Blocking the CD70-CD27 interaction inhibits LSC proliferation and prolongs survival. WT CML mice were treated i.p. every other day with 300 $\mu \mathrm{g}$ FR70 or control IgG from rat serum starting at the day of transplantation. (A) Numbers of BCR/ABL-GFP+ granulocytes/ $\mu$ in blood $(n=5$ animals per group). (B) Kaplan-Meier survival curves. Pooled data from 2 independent experiments with FR70-treated (dotted line, $n=10$ ) or IgG-treated (black line, $n=9$ ) animals are shown. (C) Numbers of lin- BCR/ABL-GFP+ myelogenous progenitor cells and (D) LSCs per mouse 20 days after transplantation ( $n=18$ mice per group, pooled data from 2 independent experiments). (E and $\mathbf{G}$ ) Immunostainings for (E) active $\beta$-catenin (spliced together from the same microscopic field of view) and (G) TNIK in LSCs from WT CML mice treated with IgG or FR70, 20 days after transplantation. Overlays of DAPI and $\beta$-catenin and DAPI and TNIK, respectively, are shown. Scale bars: $10 \mu \mathrm{m}$. (F and H) Percentages of LSCs positive for $(\mathbf{F})$ nuclear active $\beta$-catenin and $(\mathbf{H})$ nuclear TNIK. 175-216 cells were analyzed per group. (I) Cell cycle analysis by DAPI staining of LSCs from IgG-treated and FR70-treated WT CML mice. (J) 20 days after primary transplantation, $3 \times 10^{6}$ BM cells from IgG-treated or FR70-treated WT CML mice were pooled and secondarily transplanted into irradiated (4.5 Gy) BL/6 mice. Kaplan-Meier survival curves resulting from secondary transplantations are shown. Data are displayed as mean \pm SEM. Statistics: 2-way ANOVA (A), log-rank test (B and J), Student's $t$ test $(\mathbf{C}, \mathbf{D}, \mathbf{F}, \mathbf{H}$, and I). Cells/mouse = cells from both femora, tibiae, and humeri. 

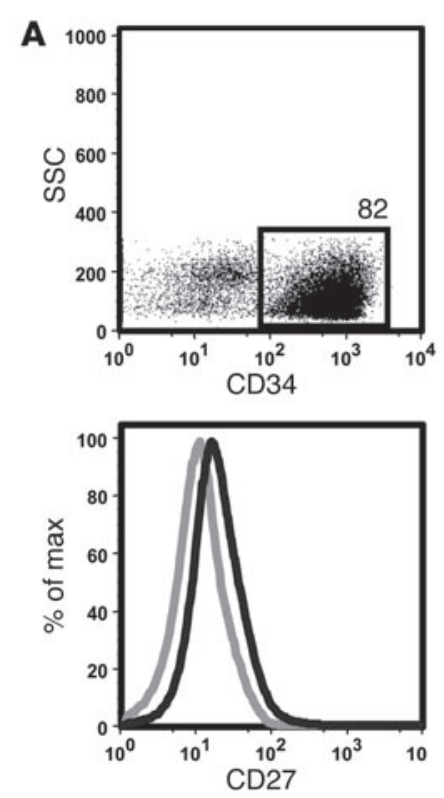

B
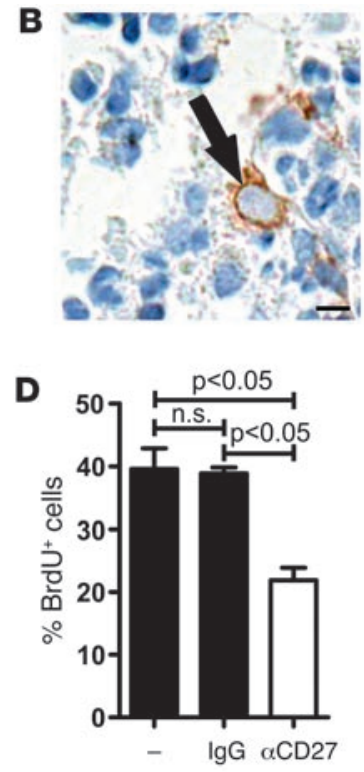

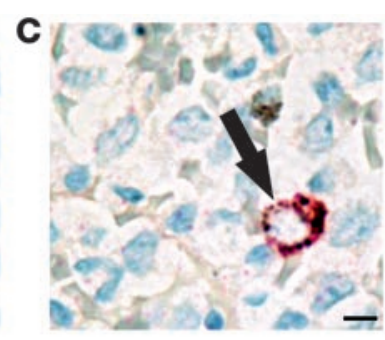

E

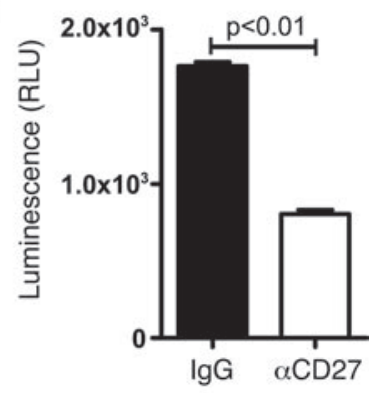

Figure 8

Expression and function of CD27 on human leukemia cells. (A) Human BM aspirates from healthy donors who underwent biopsy for reasons other than leukemia were enriched for CD34+ cells by MACS, and expression of CD34 and CD27 were analyzed by FACS. 1 representative experiment out of 3 is shown. Gray line, isotype control; black line, CD27 staining. (B and C) Representative immunohistochemistries for (B) CD27 (brown) and (C) CD34 (brown) and CD27 (red) on BM biopsy samples of untreated CML patients $(n=10)$. Scale bars: $5 \mu \mathrm{m}$. Black arrows indicate CD27+ progenitor/stem cells. 7,500-17,000 cells/biopsy were analyzed. (D) $10^{5} \mathrm{BCR} / \mathrm{ABL}+\mathrm{SD}-1$ cells were cultured in the presence or absence of $10 \mu \mathrm{g} / \mathrm{ml}$ mouse control IgG or blocking anti-CD27 Ab for 3 days. For the last 4 hours of culture, $10 \mu \mathrm{M}$ of BrdU was added to the medium; cells were then harvested and BrdU incorporation was analyzed by FACS. Each condition was run in duplicate. (E) Tcf/Lef luciferase reporter assay of SD-1 cells cultured in the presence of mouse IgG control Ab or CD27 blocking mAb for 24 hours. Each condition was run in duplicate. Data are displayed as mean \pm SEM. Statistics: 1-way ANOVA (D); Student's $t$ test (E).

CML. The treatment of WT CML mice with CD70-blocking Ab FR70 delayed CML progression and prolonged survival when compared with WT CML mice treated with control IgG (Figure 7, A and B). FR70 treatment reduced numbers of myelogenous leukemia progenitor cells and LSCs (Figure 7, C and D, and Supplemental Figure 12), as analyzed by FACS 20 days after transplantation. Furthermore, in analogy to what we observed in WT and Cd27-/- LSCs, significantly lower amounts of active $\beta$-catenin and TNIK were detected in nuclei of FACS-sorted LSCs from FR70-treated mice (Figures 7, E-H). This resulted in reduced proliferation of LSCs in FR70-treated CML animals (Figure 7I). To define the effect of FR70 treatment on LSCs in vivo in more detail, we performed a secondary transplantation of IgG- or FR70-treated CML. Twenty days after primary transplantation, we secondarily transplanted $3 \times 10^{6}$ whole BM cells from IgGor FR70-treated WT CML mice into irradiated (4.5 Gy) BL/6 mice. Mice that received FR70-treated CML BM survived significantly longer than mice that received IgG-treated CML BM (Figure 7J).

Of note, treatment with FR70 Ab blocked CD70-CD27 interactions not only on the LSC level, but also on lymphocytes, possibly resulting in impaired activation of $\mathrm{T}$ cells $(15,22)$. Therefore, despite these negative effects on $\mathrm{T}$ cell activation, blocking CD70CD27 interaction prolonged overall survival of WT CML mice.

CD27 is expressed on buman CML progenitor cells. To validate the significance of our findings for human disease, we first analyzed the expression of CD27 on MACS-enriched CD34+ BM cells in aspirations from patients that underwent BM biopsy for other reasons than leukemia (healthy donors). CD34+ BM cells expressed CD27 as analyzed by FACS (Figure 8A). In a next step, BM biopsies from 10 untreated, newly diagnosed CML patients (mean age: 50 years, range: 26-72 years; mean leukocyte count: $70 \times 10^{9} / 1$, range: $\left.17-160 \times 10^{9} / 1\right)$ were examined by 2 surgical pathologists for CD27 expression and coexpression with CD34 by immunohistochemistry. In all cases, CD27-positive cells could be found that fulfilled the morphological criteria of mature lymphocytes and plasma cells. Besides, CD27-positive cells $(0.025 \% \pm 0.004 \%$ of all nucleated cells) were found displaying the morphological characteristics of myeloid progenitor/stem cells with enlarged, centrally located nuclei and immature chromatin (Figure 8B). In double stainings, such cells stained positive for both CD34 and CD27 (Figure 8C). In every single case, adequate internal controls stained as expected: vessels, $\mathrm{CD} 34^{+}$and $\mathrm{CD} 27^{-}$; mature myeloid cells, CD27-; and plasma cells, CD27 (data not shown).

To functionally analyze CD27 signaling in human leukemia cells, we used the $\mathrm{BCR} / \mathrm{ABL}^{+}$leukemia cell line $\mathrm{SD}-1$, which expresses both CD27 and CD70 (data not shown). Blocking CD27 signaling by monoclonal anti-CD27 Ab resulted in reduced cell proliferation (Figure 8D) compared with untreated or control IgG-treated cells. However, blocking CD27 did not affect apoptosis, as analyzed by annexin $\mathrm{V}$ stainings (data not shown). In addition, we analyzed the activation of the Wnt pathway in SD-1 cells treated with anti$\mathrm{CD} 27 \mathrm{Ab}$ or control IgG. Blocking CD27 strongly reduced Tcf/Lef reporter activity (Figure $8 \mathrm{E}$ ).

The CD27-TRAF2-TNIK signaling axis induces the Wnt pathway in buman leukemia cells. To investigate the intracellular CD27 signaling pathway in human leukemia cells in more detail, we first 
A

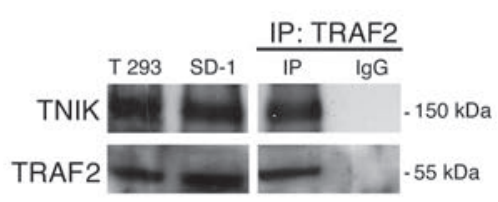

B
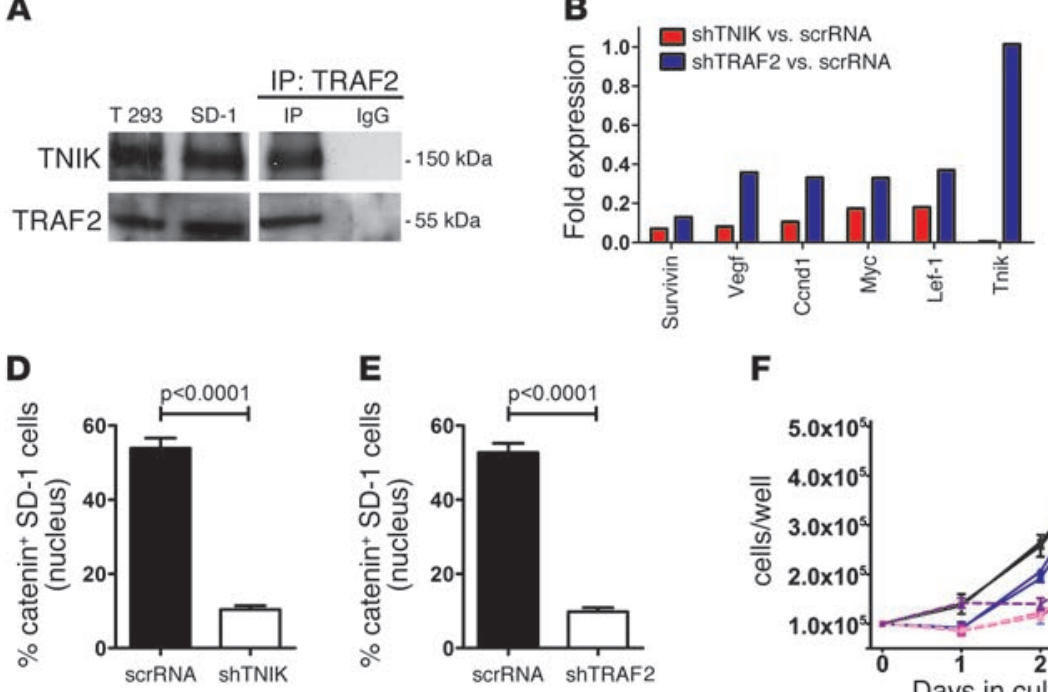

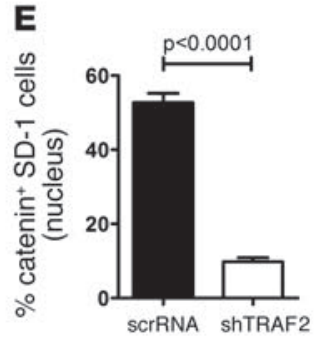

$\mathbf{F}$

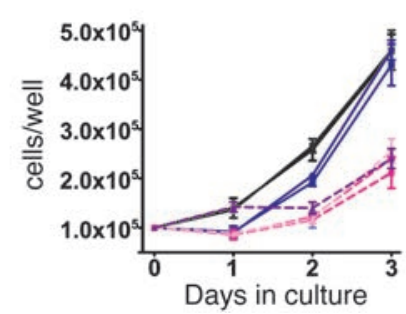

C

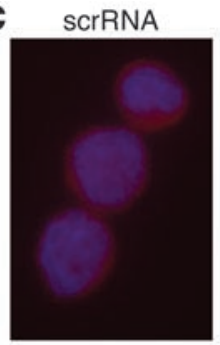

ShTNIK

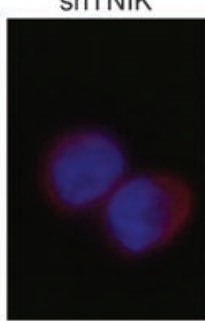

G

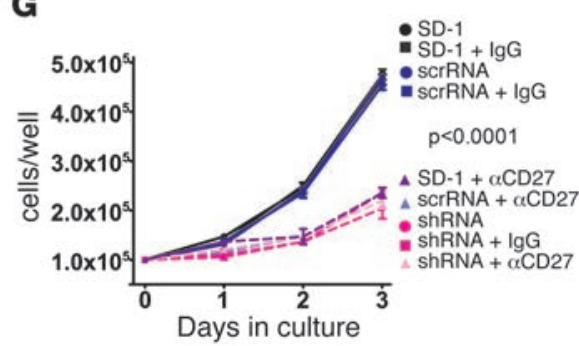

Figure 9

CD27-TRAF2-TNIK signaling induces the Wnt pathway in human leukemia cells. (A) Expression of TNIK and TRAF2 in BCR/ABL+ SD-1 cells and control T293 cells (left panel) and immunoprecipitation for TRAF2 in SD-1 cells, followed by Western blot for TRAF2 and TNIK (right panel). (B) Quantitative real-time RT-PCR of selected Wnt target genes in SD-1 cells stably expressing a scrambled shRNA (scrRNA), an shRNA against TNIK (shTNIK), or TRAF2 (shTRAF2). (C) Immunostainings for active $\beta$-catenin in SD-1 cells stably expressing scrRNA, shTNIK, or shTRAF2. Overlays of DAPI and $\beta$-catenin are shown. Scale bars: $5 \mu \mathrm{m}$. (D and E) Percentages of nuclear active $\beta$-catenin in SD- 1 cells stably expressing (D) scrRNA versus shTNIK and (E) scrRNA versus shTRAF2. 110-226 cells were analyzed per group in 2 independent experiments. (F and G) $10^{5}$ parental SD-1 cells, SD-1 cells stably expressing scrRNA, (F) shTNIK, or (G) shTRAF2 were cultured in the presence or absence of 10 $\mu \mathrm{g} / \mathrm{ml}$ mouse control IgG or blocking anti-CD27 Ab. Numbers of viable cells were daily determined by trypan blue staining. Each condition was run in duplicate in 2 independent experiments. Data are displayed as mean \pm SEM. Statistics: Student's $t$ test $(\mathbf{D}$ and $\mathbf{E})$; 2-way ANOVA (F and G) ( $P$ value indicates comparison of each of the upper 4 versus each of the lower 5 conditions).

performed coimmunoprecipitation studies for the interaction of TRAF2 and TNIK. This interaction has been described before by Fu et al. in T293 cells (26). Western blot analysis revealed that both TNIK and TRAF2 are expressed in SD-1 cells and T293 control cells (Figure 9A). More importantly, TNIK coimmunoprecipitated with TRAF2, indicating that these molecules functionally interact in SD-1 cells (Figure 9A).

To analyze the role of TRAF2 and TNIK on the expression of Wnt target genes and the subcellular localization of active $\beta$-catenin, we stably silenced TNIK or TRAF2 in SD-1 cells by shRNAs and compared these with scrambled RNA-expressing control cells. Wnt target genes were approximately 3-fold downregulated after knockdown of TNIK or TRAF2 in SD-1 cells (Figure 9B). Furthermore, knockdown of TNIK or TRAF2 resulted in significantly lower amounts of nuclear active $\beta$-catenin in SD- 1 cells (Figure 9, C-E).

In addition, we investigated the effect of TNIK or TRAF 2 knockdowns on the growth of SD-1 cells in comparison with treatment with blocking anti-CD27 mAb. TNIK (Figure 9F) or TRAF2 (Figure 9G) knockdowns had an inhibitory effect on SD-1 cell growth similar to that of blocking CD27 signaling. Importantly, combining knockdowns of TNIK or TRAF2 with anti-CD27 Ab treatment did not additionally inhibit cell growth, indicating that the effect of CD27 signaling on SD-1 cell proliferation is exclusively mediated via TRAF2/TNIK.

In summary, these findings indicate that CD27 is expressed on $\mathrm{CD} 34^{+}$cells in the BM of healthy donors and CML patients and that CD27 signaling on leukemia cells increases Wnt pathway activity via TRAF2/TNIK.

\section{Discussion}

In addition to the tumor-protective role of the host immune system, it has become increasingly evident that parts of the host immune responses favor tumor progression (31). In the present study, we provide evidence that CD27 signaling on LSCs and early myelogenous leukemia progenitors promotes leukemia progression. Previous studies have already demonstrated that CD27 is differentially expressed on murine HSCs, subdividing the HSC population into cells with short-term $\left(\mathrm{CD} 27^{+}\right)$and long-term (CD27-) hematopoietic activity (16). In contrast, the expression and function of CD27 on LSCs has not been analyzed so far.

Like HSCs, LSCs and myelogenous leukemia progenitor cells, but not differentiated granulocytes, express CD27. However, LSCs and leukemia progenitor cells consist of a CD27hi and a CD27lo/neg population. Blocking the CD70-CD27 interaction with FR70 Ab in vivo resulted in upregulation of CD27 on CD27/o/neg LSCs, indicating recent $\mathrm{CD} 70-\mathrm{CD} 27$ ligation in vivo and consequent shedding of CD27 (12). CD70 is expressed on activated lymphocytes and subsets of mature DCs and, indeed, activated $\mathrm{CD}^{+}$and $\mathrm{CD} 4^{+}$ T cells and NK cells have been documented in CML patients (32, 33). In addition, we documented CD70 expression in BM-infiltrating immune cells in CML, preferentially by $\mathrm{CD}^{+} \mathrm{T}$ cells.

LSCs possess biological features that are different from those of HSCs and are crucially important for their malignant characteristics (34-36). CD27 signaling on HSCs and early progenitor cells decreased leukocyte differentiation (17). In contrast, we found increased numbers of LSCs and all subsequent differentiation steps including myelogenous leukemia CMPs, GMPs, and differentiated 


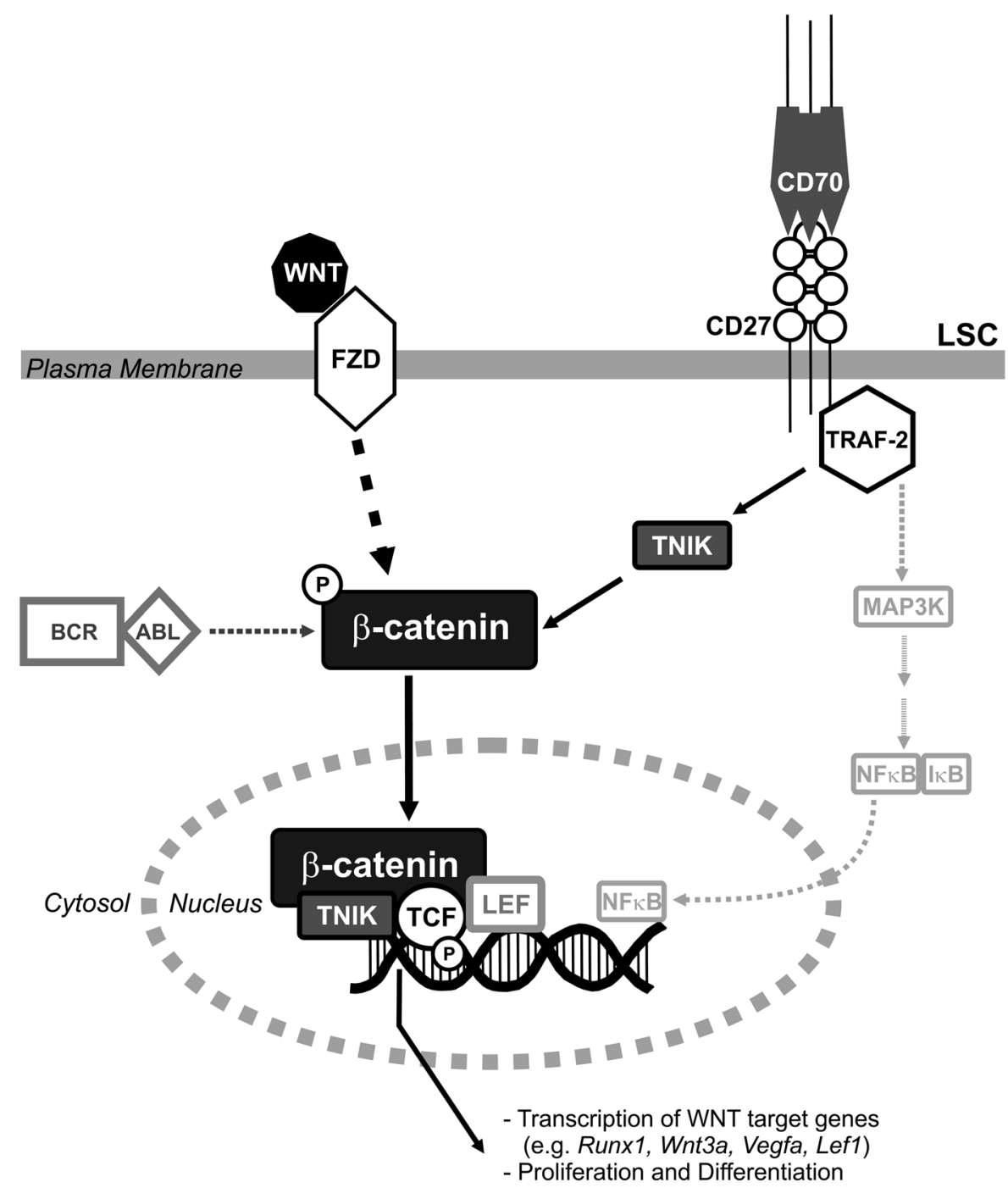

\section{Figure 10}

Model of CD27-induced Wnt pathway activation in LSCs. Binding of Wnt proteins to FZD leads to activation of $\beta$-catenin in the cytoplasm. Subsequently, TNIK binds to active $\beta$-catenin and this complex is recruited to the nucleus, where TNIK directly phosphorylates Tcf, converting the Tcf/Lefcomplex from a transcriptional repressor into a transcriptional activator of Wnt target genes. In CML, the Wnt signaling pathway is constantly activated by BCR/ABL-mediated tyrosine phosphorylation of active $\beta$-catenin, resulting in enhanced stability and leading to pathological LSC proliferation/differentiation. CD27 signaling leads to recruitment of TRAF2 and subsequent activation of TNIK, promoting nuclear translocation of the active $\beta$-catenin/TNIK complex. Thereby, CD27 signaling contributes to increased transcription of Wnt target genes. granulocytes in CML mice with intact CD27 signaling on LSCs. This difference may be explained by the fact that the tyrosine kinase $\mathrm{BCR} / \mathrm{ABL}$ by itself mediates effects on signal transduction pathways affecting cell survival, proliferation, and differentiation. BCR/ $\mathrm{ABL}^{+} \mathrm{LSCs}$ and committed leukemia progenitors are capable of self renewal (37-41). We have now found that CD27 signaling increases the number of LSCs by inducing cell division and proliferation.

Various pathways have been identified that are involved and cooperate in HSC self renewal and proliferation, such as the Notch and Wnt pathways $(24,42-44)$. Alterations in Wnt signaling have been reported in hematopoietic malignancies such as acute lymphoblastic leukemia, myelodysplastic syndromes, and CML (44-48). Surprisingly, we found that CD27 signaling activated the Wnt pathway and upregulated Wnt target genes. It is well documented that triggering CD27 leads to recruitment of TRAF2 to its cytosolic domain. TRAF2 serves as an adaptor protein for kinases to orchestrate common signaling pathways, such as the NF- $\mathrm{\kappa B}$ pathway and the JNK/AP1 and PI3K/Akt pathways (49), but a link to the Wnt pathway has not yet been documented. Recently, TNIK was shown to be an essential activator of the Wnt pathway in colorectal cancer (26-28). Our results indicate that TNIK is expressed in HSCs and LSCs and, therefore, may link CD27 signaling to the Wnt path- way. Importantly, active $\beta$-catenin and TNIK were preferentially localized in the nucleus of WT LSCs, but not of $C d 27^{-/-}$or FR70treated LSCs. The $\beta$-catenin/TNIK complex is essential for the TNIK-mediated phosphorylation of Tcf4 and subsequent Tcf4/ Lef-driven transcriptional activation of Wnt target genes (27).

To functionally analyze whether CD27 signaling induces proliferation of LSCs via the Wnt pathway, we inhibited $\beta$-catenin in vitro by indomethacin (30). In the presence of indomethacin, the effect of CD27 signaling on LSC proliferation was completely blocked. Additional stimulation of the Wnt pathway by providing exogenous Wnt-3a did not further increase colony formation, indicating saturation in the extracellular activation of Wnt signaling through frizzled (FZD) receptors on LSCs. In contrast, addition of the extracellular Wnt antagonist Sfrp-2 blocked the effect of CD27 stimulation. This suggests that CD27-mediated signaling to $\beta$-catenin is dependent on extracellular, probably autocrine-secreted, Wnt ligands and indicates that TNIK/ $\beta$-catenin is the main pathway of CD27 signalinginduced proliferation of LSCs. In CML, active $\beta$-catenin is stabilized by BCR/ABL-mediated tyrosine phosphorylation (25). We propose that BCR/ABL and CD27 cooperate at the level of $\beta$-catenin/TNIKinduced transcriptional activation of Wnt target genes to drive LSC proliferation and CML progression (Figure 10). 
CML stem cells seem resistant to most therapeutic interventions, such as chemotherapy, irradiation, and administration of tyrosine kinase inhibitors. Even during therapy, quiescent, self-renewing LSCs remain in the BM and are responsible for the refractoriness and relapse of CML (50). Therefore, a possible curative treatment must target LSCs. Our results indicate that CD27 signaling enhances LSC proliferation and expansion and promotes disease progression via the Wnt pathway, an essential pathway for self renewal of HSCs and CML LSCs (51). In our model, only LSCs and leukemia progenitors were CD27 deficient, whereas the immune system of the mouse was CD27 competent. However, treatment of WT CML mice with a monoclonal CD70-blocking Ab indicated that disease progression is delayed and survival is prolonged despite the fact that CD27 signaling was blocked on both LSCs and lymphocytes.

In 1995, Lansdorp et al. reported that CD27 is not expressed on CD34+ BM cells (52). In contrast, we demonstrate CD27 expression by FACS on CD34+ BM cells of healthy donors. In addition, we show by immunohistochemistry that morphologically identified and $\mathrm{CD} 34^{+}$progenitor/stem cells from CML patients express CD27. In parallel to our findings in the murine CML model, the CD27-TRAF2-TNIK signaling axis activated the Wnt pathway and induced proliferation of a human $\mathrm{BCR} / \mathrm{ABL}^{+}$leukemia cell line.

In summary, our data indicate that blocking the CD70-CD27 interaction or targeting intracellular mediators of the CD27 signaling pathway may provide an additional therapeutic option for treating CML on the level of LSCs. In this study, we identified CD27 signal transduction as a new link between the immune system and Wnt signaling/leukemia development in CML. Wnt signaling is essential for LSC and leukemia GMP development and self renewal in CML and other types of leukemia, such as acute myelogenous leukemia and acute lymphoblastic leukemia (29, 39, $51,53)$. Further studies will reveal whether targeting CD27 signaling to inhibit the Wnt/ $\beta$-catenin pathway is a therapeutic opportunity in acute leukemia as well.

\section{Methods}

Mice. BL/6 mice were from RCC Ltd., Cd27-/- mice (BL/6 background) were from J. Borst (National Cancer Institute, Amsterdam, The Netherlands) (22), and Cd70tg mice (BL/6 background) were from R. van Lier (University of Amsterdam, Amsterdam, The Netherlands) (54). Animal experiments were approved by the Veterinary Office of the Canton Bern and performed according to Swiss laws for animal protection.

Patients. Aspirations from patients that underwent BM biopsy for reasons other than leukemia (healthy donors, $n=3$ males; age, 19-43 years) were obtained at the University Hospital Bern in 2011. BM biopsy samples were obtained from randomly selected untreated CML patients $(n=10,6$ females, 4 males; age, 26-72 years) diagnosed at the Institute of Pathology at the University Hospital Basel between 2008 and 2010. All CML patients possessed a BCR/ABL translocation as tested by molecular analysis from the blood. Analysis of BM samples was approved by the local ethical committees, and all patients gave written informed consent.

Abs. $\alpha$-CD27 PE and allophycocyanin (APC), $\alpha$-CD16/32-PE-Cy7, $\alpha$-c-kitPE-Cy7 and $\alpha$-c-kit-APC-Alexa Fluor 750, $\alpha$-Sca-1-PerCP-Cy5.5 (where PerCP indicates perinidin-chlorophyll protein), and $\alpha$-Sca-1-APC, $\alpha$-Ly6GPE, $\alpha$-Gr1-APC, $\alpha$-IL-7R $\alpha$-biotin, $\alpha$-CD3e-biotin, $\alpha$-CD19-biotin, $\alpha$-Gr1biotin and $\alpha$-Ter119-biotin were from eBioscience. $\alpha$-BrdU-PE (3D4) and isotype and 7-amino-actinomycin-D (7-AAD) were from BD Pharmingen. Annexin V-biotin was produced as described (55). $\alpha$-CD70 (FR70) was from BioXCell, and IgG from rat serum was from Sigma-Aldrich. $\alpha$-CD27 (1A4) and mouse IgG1 (15H6) were from Beckman Coulter.
Retroviral particles. The retroviral vector pMSCV-p210BCR/ABL-IRES-GFP and the packaging vector pIK6 were a gift from J. Schwaller (University of Basel). Retroviral particles were produced and titrated as described $(9,10)$.

CML model. CML was induced and monitored as described $(9,10)$. Briefly, $4 \times 10^{6} \mathrm{BM}$ cells of 5-fluorouracil-pretreated mice were transduced twice in transplant medium with $1 \times 10^{5}$ retroviral particles through spin infection. $1 \times 10^{5}$ transduced BM cells were injected i.v. into previously irradiated (4.5 Gy) BL/ 6 recipient mice. $5 \times 10^{5}$ transduced BM cells were incubated for 3 days in transplant medium, and GFP expression was analyzed by FACS.

Starting from 2 weeks after transplantation, mice were daily monitored for signs of morbidity (weight loss, failure to groom, abnormal gait, and posture) and were repeatedly bled for determination of blood granulocyte numbers. Mice were euthanized when granulocyte counts reached more than $10^{5} / \mu \mathrm{l}$, when more than $20 \%$ of weight before transplantation was lost, or when failure to groom or abnormal gait or posture was present. Mice were dissected, gross anatomy of lungs, liver, and spleen was analyzed, and spleen weights were measured.

Blood smears and cytospins. Methodology for blood smears and cytospins is described in ref. 9.

Lineage depletion and flow cytometry. BM lineage depletion was performed using biotinylated Abs against red cell precursors ( $\alpha$-Ter119), B cells ( $\alpha$-CD19), T cells ( $\alpha$-CD3e), and myeloid cells ( $\alpha$-Gr1), MACS $\alpha$-biotin beads, and LS columns (Miltenyi Biotec). For analysis of myeloid progenitors, lymphoid progenitors were removed by adding $\alpha$-IL-7R $\alpha$-biotin.

Determination of granulocyte counts/ $\mu \mathrm{l}$ was performed using Trucount Tubes (BD Biosciences). All samples were analyzed on a BD LSRI, and sorting was performed on a BD FACSAria (BD Biosciences). Data were analyzed using FlowJo software (TreeStar).

BrdU incorporation and cell cycle analysis. Animals were administered BrdU $(0.8 \mathrm{mg} / \mathrm{ml}$; Sigma-Aldrich) in drinking water for 8 days. FACS-sorted HSCs and LSCs were pooled and incubated in 1\% PFA/PBS, 0.05\% Tween20 overnight at $4^{\circ} \mathrm{C}$. Samples were incubated in 125 Kunitz units DNase-I (Sigma-Aldrich) per $250 \mu \mathrm{l}$ DNase buffer $\left(4.2 \mathrm{mM} \mathrm{MgCl}_{2}, 0.15 \mathrm{M} \mathrm{NaCl}\right.$; $\mathrm{pH}$ 5) for 1 hour at $37^{\circ} \mathrm{C}$. Staining was performed with $\alpha$-BrdU-PE or isotype control-PE for 30 minutes at room temperature. For cell cycle analysis, FACS-sorted HSCs and LSCs were pooled and incubated in 1\% PFA/PBS overnight at $4^{\circ} \mathrm{C}$. Samples were permeabilized with $0.2 \%$ Triton X-100 for 30 minutes at $4^{\circ} \mathrm{C}$ and labeled with $5 \mu \mathrm{g} / \mathrm{ml}$ DAPI (Roche).

Colony forming assays. $5 \times 10^{3} \mathrm{FACS}$-sorted HSCs or LSCs from CML mice were incubated overnight in transplant medium with a 10-fold excess of MACS-purified, irradiated (10 Gy) BL/6 or CD70-Tg CD19+ B cells in 96well $\mathrm{V}$-bottom plates, followed by transfer into methocult base medium (Stemcell Technologies) supplemented with 15\% FCS, 20\% BIT (50 mg/ $\mathrm{ml} \mathrm{BSA}$ in IMDM, $1.44 \mathrm{U} / \mathrm{ml}$ recombinant-human ( $\mathrm{rh}$ ) insulin [Actrapid; Novo Nordisk] and $250 \mathrm{ng} / \mathrm{ml}$ human holo transferrin [Prospec]), $100 \mu \mathrm{M}$ 2 - $\beta$-mercaptoethanol, $2 \mathrm{mM}$ L-glutamine, penicillin/streptomycin, and $50 \mathrm{ng} / \mathrm{ml}$ recombinant-mouse SCF ( $\mathrm{rmSCF}$ ), $10 \mathrm{ng} / \mathrm{ml} \mathrm{rm}-\mathrm{IL}-3,10 \mathrm{ng} / \mathrm{ml}$ rh-IL-6 and $50 \mathrm{ng} / \mathrm{ml} \mathrm{rm-Flt3-ligand} \mathrm{(all} \mathrm{from} \mathrm{Prospec).} \mathrm{In} \mathrm{some} \mathrm{experi-}$ ments, $60 \mu \mathrm{M}$ indomethacin (Sigma-Aldrich), $10 \mathrm{mM}$ lithium chloride (Sigma-Aldrich), 1 g / $/ \mathrm{ml} \mathrm{Sfrp-2} \mathrm{(R \& D} \mathrm{Systems),} \mathrm{or} 100 \mathrm{ng} / \mathrm{ml} \mathrm{Wnt-3a}$ (R\&D Systems) was added to cultures. Colonies and cells were enumerated after 7 days ( $\geq 30$ cells/colony).

Real-time RT-PCR. LSCs were FACS sorted and pooled into RNAprotect Cell Reagent (QIAGEN), and RNA was extracted and purified using the RNeasy Mini Kit (QIAGEN). Reverse transcription was performed using 100 ng of RNA, random oligonucleotides, and AMV-RT (Roche). For quantitative real-time RT-PCR, we used TaqMan Gene Expression Assays for TNIK, Runx1, Wisp1, Notch1, Cond1, Myc, Hoxb4, human $c-A b l$, Gapdh, and $\beta$-actin (Applied Biosystems). Readouts of plates and analysis of data were performed on an ABI 7500 system and SDS2.3 software (Applied Biosystems). 
Real-time RT-PCR array. Reverse transcription was performed on $100 \mathrm{ng}$ of RNA using the RT² Nano PreAMP cDNA Synthesis Kit (SABiosciences). cDNA was amplified using the RT ${ }^{2}$ Nano PreAMP cDNA Primer Mix specific for the Hematopoietic Stem Cells and Hematopoiesis PCR Array (SABiosciences). Quantitative real-time RT-PCR was performed with $\mathrm{RT}^{2} \mathrm{SYBR}$ Green/ROX qPCR Master Mix (SABiosciences) on the Hematopoietic Stem Cells and Hematopoiesis RT2 Profiler PCR Array (SABiosciences) using an ABI 7300 system (Applied Biosystems). Differences in gene expression were calculated using the software supplied on the SABiosciences website.

Genomic real-time PCR. $10 \mathrm{mg}$ of spleens from primary and secondary $\mathrm{BL} / 6$ $\mathrm{CML}$ and $\mathrm{Cd} 27^{-/}$mice were collected, and genomic DNA was extracted and purified using the DNeasy blood and tissue kit (QIAGEN). For quantitative real-time PCR, we designed DNA primers and probes for human $\mathrm{ABL}$ (forward: 5'-AGGACAGCTCTTGATTTG-3'; reverse: 5'-GACAGATGGAAAGGACATG3'; probe: 5'-AAACAGGGTGCTAAAGCCAAC-3') and murine c-abl (forward: 5'-CTGCACTTGAAACTTCTC-3'; reverse: 5'-TACCGTCATTGAGCTATTC3'; probe: 5'-CACAGCCAGTCTCAGTTCAGG-3'). Probes were labeled at 5' with FAM and at 3' with BHQ-1 (Microsynth). 50 ng of DNA was analyzed by PCR amplification. Readouts of plates and analysis of data were performed on an ABI 7900 system and SDS2.3 software (Applied Biosystems).

Lentivirus-based reporter assay. In vitro Tcf/Lef reporter assay was performed as described (56). Briefly, $5 \times 10^{3}$ FACS-sorted LSCs from pooled WT or Cd27-/- CML animals were plated into individual wells of a 96-well U-bottom plate in IMDM without antibiotics, supplemented with $10 \%$ FCS, 50 $\mathrm{ng} / \mathrm{ml} \mathrm{rm}-\mathrm{SCF}, 10 \mathrm{ng} / \mathrm{ml} \mathrm{rh}-\mathrm{IL}-11,10 \mathrm{ng} / \mathrm{ml} \mathrm{rm}-\mathrm{TPO}$, and $50 \mathrm{ng} / \mathrm{ml} \mathrm{rm}$ Flt3-ligand (all from Prospec). Individual wells were transduced overnight at $37^{\circ} \mathrm{C}$ and $5 \% \mathrm{CO}_{2}$ with Tcf/Lef lentiviral particles expressing fireflyluciferase or the respective positive and negative control lentiviral particles (Cignal Lenti Tcf/Lef reporter [luc] kit; SABiosciences) at an MOI of 25, in the presence of $8 \mu \mathrm{g} / \mathrm{ml}$ SureEntry transduction reagent (SABiosciences) according to the manufacturer's instructions. After 18 hours, medium was removed and LSCs were incubated in the presence or absence of a 10-fold excess of MACS-purified, irradiated (10 Gy) BL/6 or CD70-Tg CD19+ B cells. SD-1 cells were transduced as described above with an MOI of 10, and stable cell lines were generated under puromycin selection $(2.5 \mu \mathrm{g} / \mathrm{ml}$; Santa Cruz Biotechnology Inc.). Luciferase activity was measured 3 days later on an Infinite 200 microplate reader (Tecan) by using the Steady-Glo Luciferase Assay System (Promega) according to the manufacturer's instructions.

Immunofluorescence. LSCs and HSCs were FACS sorted on glass slides, fixed, and blocked with $5 \%$ goat serum $/ 1 \%$ BSA in $0.1 \%$ PBS-Tween- 20 for 1 hour. After washing, slides were incubated for 2 hours with $\alpha$-active- $\beta$ catenin (8E7; Millipore), followed by incubation with $\alpha$-mouse IgG-Alexa Fluor 594 (Invitrogen) for 90 minutes. Slides were counterstained with $10 \mu \mathrm{g} / \mathrm{ml}$ DAPI. For TNIK immunostainings, slides were stained with amouse-TNIK-Ab (Santa Cruz Biotechnology Inc.) and $\alpha$-rabbit-IgGAlexa Fluor 594 (Invitrogen). Images were captured on an Eclipse E800 microscope with a DXM-1200 camera and analyzed using NIS Elements BR 3.0 software (Nikon Instruments).

TNIK/TRAF2 knockdown. TNIK and TRAF2 were silenced in the human leukemia cell line SD-1 (BCR/ABL $)$ using transduction-ready viral particles for gene silencing (Santa Cruz Biotechnology Inc.). Briefly, $5 \times 10^{4}$ SD- 1 cells were transduced overnight at $37^{\circ} \mathrm{C}$ and $5 \% \mathrm{CO}_{2}$ with $2 \times 10^{5}$ infectious units of virus of shTNIK lentiviral particles or the respective control scrambled RNA lentiviral particles (Santa Cruz Biotechnology Inc.) in the presence of $5 \mu \mathrm{g} / \mathrm{ml}$ polybrene (Sigma-Aldrich) according to the manufacturer's instructions. After 18 hours, medium was removed and cells were cultured in medium supplemented with $2.5 \mu \mathrm{g} / \mathrm{ml}$ puromycin to select for stable expression of shTNIK or scrambled RNA.

Immunohistochemistry. BM biopsy slides were immunohistochemically stained using an automated immunostainer (Benchmark XT). Briefly, for single stainings, slides were deparaffinized, pretreated with CC1 Buffer, and incubated with anti-human CD27 (clone 137B4, dilution 1:40; Novocastra) for 120 minutes at room temperature. Ab was detected with iView Universal DAB kit (brown, Ventana). For double stainings, slides were deparaffinized, pretreated with CC1, and incubated first with CD34 (clone QBEnd/10 dilution, as provided by manufacturer; Ventana) for 60 minutes at room temperature and detected with iView Universal DAB kit (brown). Afterwards, slides were stained with CD27 for 120 minutes at room temperature and detected with iView Universal DAB Kit (red). Images were captured on an Eclipse E800 microscope with a DXM-1200 camera and analyzed using NIS Elements BR 3.0 software (Nikon Instruments).

Immunoprecipitation and Western blot analysis. SD-1 cells were lysed in icecold radioimmunoprecipitation buffer $(20 \mathrm{mM}$ Tris-HCl, $\mathrm{pH} 7.4,1 \%$ Triton $\mathrm{X}-100,150 \mathrm{mM} \mathrm{NaCl}, 2 \mathrm{mM}$ EDTA, 2 mM EGTA containing a mixture of protease inhibitors; Roche) for 30 minutes at $4^{\circ} \mathrm{C}$, followed by centrifugation at $14,000 \mathrm{~g}$ for 15 minutes at $4^{\circ} \mathrm{C} .50 \mu \mathrm{g}$ of cell lysate was precleared by adding $20 \mu \mathrm{l}$ of Protein A/G Plus agarose beads and subsequently incubated with rabbit anti-TRAF2 (clone: H-249; Santa Cruz Biotechnology Inc.) overnight at $4^{\circ} \mathrm{C}$ with gentle tumbling. $20 \mu \mathrm{l}$ of agarose beads was added to the lysate for 2 hours at $4^{\circ} \mathrm{C}$ with gentle tumbling. The agarose beads were washed 3 times with ice-cold wash buffer $(5 \mathrm{mM}$ Tris- $\mathrm{HCl}, \mathrm{pH}$ 7.4, $20 \mathrm{mM} \mathrm{NaCl}$, and $0.5 \%$ Triton $\mathrm{X}-100$ ) and resuspended in $20 \mu \mathrm{l}$ of $2 \times$ sample buffer, followed by elution through boiling.

Proteins were separated on a 4\%-20\% gradient SDS-PAGE gel (Bio-Rad), blotted onto a polyvinylidene difluoride membrane (Sigma-Aldrich), and stained with rabbit $\alpha$-TRAF2 (clone H-249; Santa Cruz Biotechnology Inc.) or mouse $\alpha$-TNIK (clone: 53; Santa Cruz Biotechnology Inc.) overnight at $4^{\circ} \mathrm{C}$. Subsequently, blots were incubated for 1 hour with donkey $\alpha$-rabbit peroxidase IgG or sheep $\alpha$-mouse peroxidase IgG (Amersham) and developed by enhanced chemiluminescence (Thermo Scientific).

Statistics. Statistical analysis was performed using GraphPad Prism 5.0 (GraphPad Software). Data are represented as mean \pm SEM. The ShapiroWilk test was used to determine whether the data meet the assumption of normality. Data were analyzed using 1-way ANOVA and Tukey's multiple comparison test, Student's $t$ test (2-tailed), 1-sample $t$ test or 2-way ANOVA, and Bonferroni's post-hoc test ( $P$ value shows interaction). Significance of differences in Kaplan-Meier survival curves was determined using the logrank test (2-tailed). $P<0.05$ was considered significant.

\section{Acknowledgments}

This work was supported by grants from the Swiss National Science Foundation, Oncosuisse, the Bernische Krebsliga, the Werner und Hedy Berger-Janser-Stiftung, and the SAKK/AMGEN Research Grant 2009 (all to A.F. Ochsenbein). C. Schürch is supported by a Swiss MD-PhD scholarship, the Gertrud HagmannStiftung für Malignomforschung, and the Swiss Life Jubiläumsstiftung, and C. Schürch and C. Riether are supported by the Fondazione per la Ricerca sulla Trasfusione e sui Trapianti and the Olga Mayenfisch Stiftung. We thank Jannie Borst for providing $C d 27^{-/-}$mice, René van Lier for providing Cd70tg mice, Jürg Schwaller for providing retroviral vectors, and Thomas Brunner for critical comments.

Received for publication December 1, 2010, and accepted in revised form November 30, 2011.

Address correspondence to: Adrian F. Ochsenbein, Institute for Medical Oncology, Inselspital, University Hospital Bern, 3010 Bern, Switzerland. Phone: 41.31.632.4114; Fax: 41.31.632.4119; E-mail: adrian.ochsenbein@insel.ch. 
1. Rowley JD. Letter: A new consistent chromosomal abnormality in chronic myelogenous leukaemia identified by quinacrine fluorescence and Giemsa staining. Nature. 1973;243(5405):290-293.

2. Lugo TG, Pendergast AM, Muller AJ, Witte ON Tyrosine kinase activity and transformation potency of bcr-abl oncogene products. Science. 1990; 247(4946):1079-1082.

3. Kavalerchik E, Goff D, Jamieson CH. Chronic myeloid leukemia stem cells. J Clin Oncol. 2008;26(17):2911-2915.

4. Faderl S, Talpaz M, Estrov Z, O’Brien S, Kurzrock R, Kantarjian HM. The biology of chronic myeloid leukemia. NEngl J Med. 1999;341(3):164-172.

5. Molldrem JJ, et al. Evidence that specific T lymphocytes may participate in the elimination of chronic myelogenous leukemia. Nat Med. 2000; 6(9):1018-1023

6. Van Driessche A, et al. Antigen-specific cellular immunotherapy of leukemia. Lenkemia. 2005;19(11):1863-1871.

7. Pierson BA, Miller JS. The role of autologous natural killer cells in chronic myelogenous leukemia. Leuk Lymphoma. 1997;27(5-6):387-399.

8. Kolb HJ, Schmid C, Barrett AJ, Schendel DJ. Graftversus-leukemia reactions in allogeneic chimeras. Blood. 2004;103(3):767-776.

9. Mumprecht S, Claus C, Schürch C, Pavelic V, Matter MS, Ochsenbein AF. Defective homing and impaired induction of cytotoxic $\mathrm{T}$ cells by BCR/ABL-expressing dendritic cells. Blood. 2009; 113(19):4681-4689.

10. Mumprecht S, Schürch C, Schwaller J, Solenthaler $\mathrm{M}$, Ochsenbein AF. Programmed death 1 signaling on chronic myeloid leukemia-specific T cells results in T-cell exhaustion and disease progression. Blood. 2009;114(8):1528-1536.

11. Gravestein LA, Borst J. Tumor necrosis factor receptor family members in the immune system. Semin Immunol. 1998;10(6):423-434

12. Nolte MA, van Olffen RW, van Gisbergen KP, van Lier RA. Timing and tuning of CD27-CD70 interactions: the impact of signal strength in setting the balance between adaptive responses and immunopathology. Immunol Rev. 2009;229(1):216-231.

13. Wajant $\mathrm{H}$, Scheurich P. Tumor necrosis factor receptor-associated factor (TRAF) 2 and its role in TNF signaling. Int J Biochem Cell Biol. 2001;33(1):19-32.

14. van Oosterwijk MF, et al. CD27-CD70 interactions sensitise naive CD4+ T cells for IL-12-induced Th1 cell development. Int Immunol. 2007;19(6):713-718.

15. Borst J, Hendriks J, Xiao Y. CD27 and CD70 in $\mathrm{T}$ cell and B cell activation. Curr Opin Immunol. 2005;17(3):275-281.

16. Wiesmann A, et al. Expression of CD27 on murine hematopoietic stem and progenitor cells. Immunity. 2000;12(2):193-199.

17. Nolte MA, et al. Immune activation modulates hematopoiesis through interactions between CD27 and CD70. Nat Immunol. 2005;6(4):412-418

18. Tesselaar K, et al. Expression of the murine CD27 ligand CD70 in vitro and in vivo. J Immunol. 2003;170(1):33-40.

19. Croft M. The role of TNF superfamily members in T-cell function and diseases. Nat Rev Immunol. 2009;9(4):271-285.

20. Neering SJ, et al. Leukemia stem cells in a geneti- cally defined murine model of blast-crisis CML. Blood. 2007;110(7):2578-2585

21. Akashi K, Traver D, Miyamoto T, Weissman IL. A clonogenic common myeloid progenitor that gives rise to all myeloid lineages. Nature. 2000;404(6774):193-197.

22. Hendriks J, Gravestein LA, Tesselaar K, van Lier RA, Schumacher TN, Borst J. CD27 is required for generation and long-term maintenance of $\mathrm{T}$ cell immunity. Nat Immunol. 2000;1(5):433-440.

23. Merchant A, Joseph G, Wang Q, Brennan S, Matsui W. Gli1 regulates the proliferation and differentiation of HSCs and myeloid progenitors. Blood. 2010;115(12):2391-2396.

24. Staal FJ, Clevers HC. WNT signalling and haematopoiesis: a WNT-WNT situation. Nat Rev Immunol. 2005;5(1):21-30.

25. Coluccia AM, et al. Bcr-Abl stabilizes beta-catenin in chronic myeloid leukemia through its tyrosine phosphorylation. EMBO J. 2007;26(5):1456-1466.

26. Fu CA, Shen M, Huang BC, Lasaga J, Payan DG, Luo Y. TNIK, a novel member of the germinal center kinase family that activates the c-Jun $\mathrm{N}$-terminal kinase pathway and regulates the cytoskeleton. J Biol Chem. 1999;274(43):30729-30737.

27. Mahmoudi T, et al. The kinase TNIK is an essential activator of Wnt target genes. EMBO J. 2009; 28(21):3329-3340.

28. Shitashige M, et al. Traf2- and Nck-interacting kinase is essential for Wnt signaling and colorectal cancer growth. Cancer Res. 2010;70(12):5024-5033.

29. Wang Y, et al. The Wnt/beta-catenin pathway is required for the development of leukemia stem cells in AML. Science. 2010;327(5973):1650-1653.

30. Goessling W, et al. Genetic interaction of PGE2 and Wnt signaling regulates developmental specification of stem cells and regeneration. Cell. 2009;136(6):1136-1147.

31. de Visser KE, Eichten A, Coussens LM. Paradoxical roles of the immune system during cancer development. Nat Rev Cancer. 2006;6(1):24-37.

32. Lim SH, Coleman S. Chronic myeloid leukemia as an immunological target. Am J Hematol. 1997; 54(1):61-67.

33. Greiner J, Schmitt M. Leukemia-associated antigens as target structures for a specific immunotherapy in chronic myeloid leukemia. Eur J Haematol. 2008;80(6):461-468.

34. Jaiswal S, et al. CD47 is upregulated on circulating hematopoietic stem cells and leukemia cells to avoid phagocytosis. Cell. 2009;138(2):271-285.

35. Krause DS, Van Etten RA. Right on target: eradicating leukemic stem cells. Trends Mol Med. 2007;13(11):470-481.

36. Majeti R, et al. CD47 is an adverse prognostic factor and therapeutic antibody target on human acute myeloid leukemia stem cells. Cell. 2009; 138(2):286-299.

37. Huntly BJ, Gilliland DG. Blasts from the past: new lessons in stem cell biology from chronic myelogenous leukemia. Cancer Cell. 2004;6(3):199-201.

38. Huntly BJ, et al. MOZ-TIF2, but not BCR-ABL, confers properties of leukemic stem cells to committed murine hematopoietic progenitors. Cancer Cell. 2004;6(6):587-596

39. Jamieson $\mathrm{CH}$, et al. Granulocyte-macrophage progenitors as candidate leukemic stem cells in blast- crisis CML. NEngl J Med. 2004;351(7):657-667.

40. Jamieson CH, Weissman IL, Passegue E. Chronic versus acute myelogenous leukemia: a question of self-renewal. Cancer Cell. 2004;6(6):531-533.

41. Rizo A, Vellenga E, de Haan G, Schuringa JJ. Signaling pathways in self-renewing hematopoietic and leukemic stem cells: do all stem cells need a niche? Hum Mol Genet. 2006;15 spec no 2:R210-R219.

42. Sandy AR, Maillard I. Notch signaling in the hematopoietic system. Expert Opin Biol Ther. 2009; 9(11):1383-1398.

43. Maillard I, et al. Canonical notch signaling is dispensable for the maintenance of adult hematopoietic stem cells. Cell Stem Cell. 2008;2(4):356-366.

44. Friedman AD. Cell cycle and developmental control of hematopoiesis by Runx1. J Cell Physiol. 2009;219(3):520-524.

45. Roche-Lestienne C, et al. RUNX1 DNA-binding mutations and RUNX1-PRDM16 cryptic fusions in BCR-ABL+ leukemias are frequently associated with secondary trisomy 21 and may contribute to clonal evolution and imatinib resistance. Blood. 2008;111(7):3735-3741.

46. Penther D, et al. Amplification of AML1 gene is present in childhood acute lymphoblastic leukemia but not in adult, and is not associated with AML1 gene mutation. Leukemia. 2002;16(6):1131-1134.

47. Mikhail FM, et al. A new translocation that rearranges the AML1 gene in a patient with T-cell acute lymphoblastic leukemia. Cancer Genet Cytogenet. 2002;135(1):96-100.

48. Miething C, et al. Retroviral insertional mutagenesis identifies RUNX genes involved in chronic myeloid leukemia disease persistence under imatinib treatment. Proc Natl Acad Sci U S A. 2007;104(11):4594-4599.

49. Croft M. Co-stimulatory members of the TNFR family: keys to effective T-cell immunity? Nat Rev Immunol. 2003;3(8):609-620.

50. Hughes TP, et al. Frequency of major molecular responses to imatinib or interferon alfa plus cytarabine in newly diagnosed chronic myeloid leukemia. NEngl J Med. 2003;349(15):1423-1432.

51. Zhao C, et al. Loss of beta-catenin impairs the renewal of normal and CML stem cells in vivo. Cancer Cell. 2007;12(6):528-541.

52. Lansdorp PM, Smith C, Thornbury G, Little MT, Dragowska W. Reactivity of workshop mAb with CD34+ bone marrow cells. In: Schlossman SF, et al., eds. Leucocyte Typing V: White Cell Differentiation Antigens. New York, New York, USA: Oxford University Press; 1995:1030-1032.

53. Eaves CJ, Humphries RK. Acute myeloid leukemia and the Wnt pathway. $N$ Engl J Med. 2010;362(24):2326-2327.

54. Arens R, et al. Constitutive CD27/CD70 interaction induces expansion of effector-type $T$ cells and results in IFNgamma-mediated B cell depletion. Immunity. 2001;15(5):801-812.

55. Martin SJ, et al. Early redistribution of plasma membrane phosphatidylserine is a general feature of apoptosis regardless of the initiating stimulus: inhibition by overexpression of Bcl-2 and Abl. J Exp Med. 1995;182(5):1545-1556.

56. Reya $\mathrm{T}$, et al. A role for Wnt signalling in selfrenewal of haematopoietic stem cells. Nature. 2003;423(6938):409-414 